\title{
Macaque-tropic human immunodeficiency virus type 1: breaking out of the host restriction factors
}

\author{
Akatsuki Saito ${ }^{1,2 *}$ and Hirofumi Akari ${ }^{1}$ \\ ${ }^{1}$ Center for Human Evolution Modeling Research, Primate Research Institute, Kyoto University, Inuyama, Japan \\ 2 Japan Foundation for AIDS Prevention, Chiyoda-ku, Japan
}

\section{Edited by:}

Tomoyuki Miura, Kyoto University, Japan

Reviewed by:

Emi E. Nakayama, Osaka University, Japan

Yoshiaki Nishimrua, National Institutes of Health, USA

\section{*Correspondence:}

Akatsuki Saito, Center for Human Evolution Modeling Research, Primate Research Institute, Kyoto University, Inuyama, Aichi 484-8506, Japan e-mail: akatsuki.saito@gmail.com
Macaque monkeys serve as important animal models for understanding the pathogenesis of lentiviral infections. Since human immunodeficiency virus type 1 (HIV-1) hardly replicates in macaque cells, simian immunodeficiency virus (SIV) or chimeric viruses between HIV-1 and SIV (SHIV) have been used as challenge viruses in this research field. These viruses, however, are genetically distant from HIV-1. Therefore, in order to evaluate the efficacy of anti-HIV-1 drugs and vaccines in macaques, the development of a macaque-tropic HIV1 (HIV-1 mt) having the ability to replicate efficiently in macaques has long been desired. Recent studies have demonstrated that host restriction factors, such as APOBEC3 family and TRIM5, impose a strong barrier against HIV-1 replication in macaque cells. By evading these restriction factors, others and we have succeeded in developing an HIV-1 mt that is able to replicate in macaques. In this review, we have attempted to shed light on the role of host factors that affect the susceptibility of macaques to HIV-1mt infection, especially by focusing on TRIM5-related factors.

Keywords: macaques, HIV-1, animal model, host factors, genetic background

\section{INTRODUCTION}

It is estimated that about 2.5 million individuals per year get infected with human immunodeficiency virus type 1 (HIV-1), a causative agent of acquired immunodeficiency syndrome (AIDS; UNAIDS Global report 2012, http://www.unaids.org/). To contain the disastrous epidemic, we need to consider effective approaches. For the pre-clinical evaluation of the anti-HIV-1 vaccines and therapy, it is necessary to have suitable animal models. Moreover, animal models would also aid for the understanding of the underlying mechanisms of HIV-1 pathogenicity. Since HIV-1 shows very narrow species specificity, being limited to human and apes, it has been quite challenging to develop an ideal animal model in which HIV-1 efficiently replicates and induces pathogenicity. Instead, many kinds of surrogate models developed as alternative strategy have provided us many important insights. In this decade, the molecular characterization of antiviral host restriction factors has dramatically progressed and shed light on the understanding of the viral specificity. These findings encouraged us to develop a novel non-human primate model for HIV-1 infection on the basis of a new concept (i.e., introduction of minimal modification to HIV-1 genome), by which the resultant virus would overcome a number of restriction factors. In this review, we summarize the history of the identification of the restriction factors and also discuss its impact and future direction on the development of HIV-1 animal models.

\section{HISTORY OF HIV-1 ANIMAL MODELS HIV-1 INFECTION IN SMALL ANIMALS}

After the identification of HIV-1 as a causative agent of AIDS, many investigators sought to develop animal models for further research (reviewed in Gardner and Luciw, 1989). Although many efforts were performed in small animals, HIV-1 did not infect rodents, such as mice and rats, due to a number of restrictions, including the inability of HIV-1 Env to use the surface molecules in these animals as binding and entry receptors (Atchison et al., 1996) and the defect of murine cyclin T1 protein to associate with HIV-1 Tat (Kwak et al., 1999). Although rabbits were once expected to show susceptibility to HIV-1 infection (Filice et al., 1988; Kulaga et al., 1989), the reproducibility of this model remains to be elucidated (Reina et al., 1993; Speck et al., 1998; Tervo and Keppler, 2010). In an attempt to overcome the limitation in using these animals, several versions of humanized mice such as SCID-hu-PBL (severe combined immunodeficiency-human peripheral blood lymphocytes) mice (Mosier et al., 1988), Rag2 ${ }^{-/-} \gamma \mathrm{c}^{-/-}$mice (Traggiai et al., 2004), NOG (NOD/Shi-scid/IL-2R $\gamma$ null) mice (Ito et al., 2002), NSG (NOD scid gamma) mice (Shultz et al., 2005), and NOD/SCID-hu BLT mice (Melkus et al., 2006), have been generated (reviewed in Berges and Rowan, 2011). To generate this model, human immune cells were implanted into immunocompromised mice. After reconstitution of engrafted immune cells, HIV-1 replication in these animals was investigated. Generally, robust HIV-1 replication and loss of peripheral $\mathrm{CD} 4^{+} \mathrm{T}$ cells is observed in infected animals. Therefore, this model system would be useful for evaluation of drugs and neutralizing antibodies against HIV-1 (Denton et al., 2008). Moreover, this model provides important insight about the viral latency and the role of accessory genes in vivo (Denton et al., 2012; Marsden et al., 2012; Sato et al., 2012). However, none or weak immune response is observed in these animals. Moreover, this model requires special surgical skills and facilities to perform experiments.

\section{HIV-1 INFECTION IN NON-HUMAN PRIMATES}

Differently from other pathogenic viruses for human such as measles and mumps, HIV-1 does not replicate in New World 
monkeys (NWMs) and Old World monkeys (OWMs). In cells from NWMs, such as squirrel monkey (Saimiri sciureus) and common marmoset (Callithrix jacchus), the cluster of differentiation 4 (CD4) and C-C chemokine receptor type 5 (CCR5) molecules function insufficiently as binding and entry receptors (LaBonte et al., 2002). On the other hand, in OWM cells, most HIV-1 enters target cells as efficiently as human cells. Interestingly, recent studies revealed that some subtypes of HIV- 1 are unable to efficiently utilize macaque $\mathrm{CD} 4$ because of the difference in the $\mathrm{C}$-terminus of the $\mathrm{D} 1$ domain of $\mathrm{CD} 4$ between human and OWMs, and therefore adaptive mutation was required for optimal efficiency (Humes and Overbaugh, 2011; Humes et al., 2012). After entering target cells, the subsequent steps of HIV-1 life cycle (i.e., uncoating and reverse transcription) are strongly abolished in OWM cells (Shibata et al., 1995; Hofmann et al., 1999). Although pigtailed macaque (Macaca nemestrina; hereafter denoted as PM) was once believed to be promising because of its higher susceptibility to HIV-1 infection as compared to other OWMs (Agy et al., 1992), the HIV-1 replication in those animals was weak and the trial of serial in vivo passage was shown to be unsuccessful (Agy et al., 1997). Among the animals examined for their susceptibility to HIV-1 infection, chimpanzees and gibbon apes were identified to have high susceptibility (Fultz et al., 1986; Lusso et al., 1988). In 1980s and 1990s, many chimpanzees were experimentally infected with HIV-1, including clinically isolated viruses and molecularly cloned viruses, resulting in a robust viral replication (Alter et al., 1984; Fultz et al., 1987, 1999; Nara et al., 1987; Prince et al., 1988). These experiments provided many important insights, including the roles of neutralizing antibody in protective immunity. While some of the infected chimpanzees experienced AIDS-related symptoms (Fultz et al., 1991; Novembre et al., 1997; O’Neil et al., 2000), most of them seemed not to develop apparent clinical symptoms (Gardner and Luciw, 1989; Johnson et al., 1993). Furthermore, there are many concerns about using chimpanzees, including ethical issues and their quite high rearing cost; therefore, researchers finally decided not to use this ape for HIV-1 research (Cohen, 2007). Therefore, the need for the development of other non-human primate models has been increasing.

\section{SIV INFECTION IN NON-HUMAN PRIMATES}

As a surrogate model, simian immunodeficiency virus (SIV) infection in Asian macaques, such as rhesus macaque (Macaca mulatta; hereafter denoted as RM) and cynomolgus macaque (Macaca fascicularis; hereafter denoted as CM) has been developed. While SIV efficiently replicates in its natural host [e.g., sooty mangabey (Cercocebus atys; hereafter denoted as SM) for SIVsm and African green monkey (Chlorocebus sabaeus; hereafter denoted as AGM) for SIVagm, respectively; Ohta etal., 1988; Kraus et al., 1989], infected animals generally do not develop immunodeficiency, unlike the course of HIV-1 infection in humans. In the 1980s, accidental transmission of SIVsm to RMs caused a lethal disease, and the symptoms were quite similar to those seen in AIDS patients (Daniel etal., 1985; Letvin et al., 1985). Thereafter, the pathogenic virus was molecularly cloned as SIVmac (Naidu et al., 1988; Kestler et al., 1990). The combination of SIVmac and RMs has been broadly utilized as a surrogate model for HIV-1 infection because of its similarity in the genome structure and pathogenicity.
Specifically, this model dramatically advanced our understanding in terms of the functional roles of the viral accessory genes in vivo (Kestler et al., 1991; Gibbs et al., 1995; Hirsch et al., 1998). Moreover, this model provided the important finding that the acquired protective immunity induced by live-attenuated vaccines was effective against homologous and heterologous SIV challenges (Daniel et al., 1992; Wyand et al., 1996, 1999).

\section{INFECTION OF CHIMERIC VIRUS BETWEEN HIV-1 AND SIV IN NON-HUMAN PRIMATES}

Accumulating evidence has demonstrated the inability of intact HIV-1 to replicate in OWM cells. Then, what kind of viral components in HIV-1 and SIV determine their host tropism? In an effort to answer this profound question, many researchers constructed chimeric viruses between HIV-1 and SIV and analyzed their viral replication in human and OWM cells. It was shown that chimeric viruses containing HIV-1-derived gag and/or vif were unable to replicate in macaque cells and that a chimeric virus encoding HIV-1-derived env on the SIVmac backbone was able to replicate in primary OWM cells (Shibata et al., 1991; Shibata and Adachi, 1992), indicating that the step of entry was not the determinant for the species specificity of HIV-1. As a consequence of vigorous investigation, Shibata et al. finally succeeded to construct a prototypic simian-human immunodeficiency virus (hereafter denoted as SHIV) clone that encodes HIV-1-derived tat, rev, vpu, and env genes on the SIVmac239 backbone (Shibata et al., 1991; Shibata and Adachi, 1992). This SHIV clone was shown to efficiently replicate in primary macaque cells. Thereafter, many groups developed several versions of SHIV. Of note, by serial passaging of apathogenic SHIV-89.6 in monkeys, Reimann et al. (1996) successfully obtained a highly pathogenic virus (SHIV89.6P) that caused rapid and complete depletion of peripheral $\mathrm{CD}^{+} \mathrm{T}$ cells, leading to simian AIDS. These chimeric viruses not only enabled us to evaluate the efficacy of antiviral immunity against HIV-1 Env but also supplied us important insights on what kind of SIVmac-derived genes are necessary to replicate in macaque cells. This SHIV model became a huge breakthrough for HIV-1 investigators; by using SHIV, the mechanism and efficacy of passive immunization (Shibata et al., 1999; Baba et al., 2000; Nishimura et al., 2002) as well as vaccine candidates (Igarashi et al., 1997; Letvin etal., 1997; Cafaro et al., 1999) were vigorously investigated. Incidentally, the lower sequence homology in RT between SIV and HIV-1 limited this model for the evaluation of antiretroviral drugs especially against RT. To overcome this limitation, RT-SHIV, which encodes HIV-1 RT in the place of SIVmac RT, was developed and used for the assessment of RT inhibitors (Uberla et al., 1995; Ambrose et al., 2004; North et al., 2005). SHIV carrying HIV-1 integrase (IN) in addition to RT was also constructed (Akiyama et al., 2008). These efforts have dramatically advanced the basic research related to HIV-1. However, since these viruses were constructed on the basis of SIVmac backbone, SHIVs are still far from HIV-1. Moreover, some pathogenic SHIV clones, such as SHIV-89.6P, show quite different phenotypes in macaques, unlike those in HIV-1 infection of humans and SIVmac infection of macaques (Feinberg and Moore, 2002). First, these SHIVs induced abnormally rapid, profound, and irreversible loss of $\mathrm{CD} 4^{+} \mathrm{T}$ cells in macaques, differently from the gradual 
decline of $\mathrm{CD} 4^{+} \mathrm{T}$ cells observed in most HIV-1-infected patients (McCune, 2001). Second, these SHIVs were somehow highly susceptible to neutralizing antibodies, while most HIV-1 isolates and pathogenic SIVs were resistant to neutralization. Therefore, earlier vaccine studies using SHIV as a challenge virus succeeded in controlling viral replication by immunization with vaccine candidates (Amara et al., 2001; Barouch et al., 2001). Notably, these outcomes were frequently observed in experiments with SHIV using C-X-C chemokine receptor type 4 (CXCR4; X4-tropic virus), or SHIV using both CXCR4 and CCR5 as co-receptors (dual-tropic virus). Since HIV-1 in human population usually uses CCR5 as a coreceptor during transmission (Schuitemaker et al., 1992), it will be straightforward to develop an R5-tropic SHIV in order to reproduce the transmission, latency, and pathogenicity of HIV-1 in macaques. In fact, R5-tropic SHIVs were recently constructed and their phenotype seemed different from those of X4-tropic SHIVs and dual-tropic SHIVs. It is thought that X4-tropic SHIV selectively infects $\mathrm{CXCR} 4^{+}$naive $\mathrm{CD} 4^{+} \mathrm{T}$ cells that are enriched in secondary lymph nodes, while most SIV and R5-tropic SHIV mainly target $\mathrm{CCR}^{+}$memory $\mathrm{CD} 4^{+} \mathrm{T}$ cells in extra-lymphoid immune effector sites such as gut, lung and genital tract, explaining the divergent clinical sequel (Harouse, 1999; Nishimura et al., 2004; Ho et al., 2005). Especially, mucosal infection with R5-tropic SHIV would be a promising tool for investigating protection and transmission of immunodeficiency viruses (Matsuda et al., 2010; Bomsel et al., 2011; Gautam et al., 2012; Moldt et al., 2012).

In spite of the usefulness of these SHIVs in experiments targeting HIV- 1 env, the low similarity in other genes, especially gag and pol, still limits the use of this virus as a challenge virus. Since cytotoxic T lymphocyte (CTL) response against Gag protein is thought to play a central role in controlling viral replication (Kiepiela et al., 2007), the absence of HIV-1-derived gag in current SHIV hampers evaluation of vaccine candidate against HIV-1 Gag. To solve this problem, we need to proceed to construct more relevant animal models of HIV-1. In this decade, our knowledge about host factors that form species barrier against HIV-1 has dramatically increased. This knowledge would permit us to develop an HIV-1 clone having the potential to replicate in macaques. Many efforts to develop a more feasible model were made by several groups as described below. Here, we summarize the role of anti-HIV1 restriction factors in macaque cells and the viral antagonists against these factors.

\section{INTRINSIC HOST FACTORS APOBEC3 FAMILY}

It has long been observed that the infectivity of vif gene-deficient HIV-1 in certain T cell lines such as H9 and CEM, as well as primary lymphocytes, was strongly decreased (Gabuzda et al., 1992; Sakai etal., 1993; Tervo and Keppler, 2010). Virions produced from these restrictive cells have less infectivity as compared to the wild-type virus. Many efforts were made to identify a cellular factor that conferred this restrictive activity. In particular, the fact that heterokaryons between permissive and restrictive cells suppressed the infectivity of the vif-deficient HIV-1 clearly suggested the existence of a potent endogenous inhibitor of HIV-1 replication in restrictive cells (Madani and Kabat, 1998; Simon et al., 1998). Finally, in 2002, the apolipoprotein B mRNA editing enzyme catalytic polypeptide $3 \mathrm{G}$ (APOBEC $3 \mathrm{G}$; hereafter denoted as $A 3 G$ ) was identified as a novel host restriction factor in human cells (Sheehy et al., 2002). A3G is expressed in various tissues including testis, ovary, spleen, and peripheral blood mononuclear cells (PBMCs; Jarmuz et al., 2002). Since A3G is a member of the cytidine deaminase enzyme, the vif-deficient virus contains many G-to-A mutations in its minus-strand genome, leading to disruption of infectivity. Moreover, the fact that deaminationdeficient mutant A3G can still inhibit vif-deficient HIV-1 implied that $\mathrm{A} 3 \mathrm{G}$ exerts its antiviral activity with deamination-dependent and deamination-independent fashion (Newman et al., 2005). In order to counteract the A3G-mediated restriction, HIV-1 has equipped its genome with vif gene and the resultant protein, Vif, efficiently inhibits A3G incorporation into progeny virions by inducing proteasome-dependent degradation of A3G (Conticello et al., 2003; Kao et al., 2003; Mehle et al., 2004). Recently, it was reported that core-binding factor beta $(\mathrm{CBF} \beta)$, a transcription regulator through RUNX binding, was required for HIV-1 Vif to degrade A3G (Hultquist et al., 2012; Jager et al., 2012). SIVmac Vif similarly recruits CBF $\beta$ in order to neutralize the RM A3G (Hultquist et al., 2012; Jager et al., 2012). It was also proposed that HIV-1 Vif suppresses human A3G activity by inhibiting the translation of A3G (Mercenne et al., 2010). Although the human genome encodes other six A3 members (A3A, B, C, DE, F, and $\mathrm{H})$ in addition to $\mathrm{A} 3 \mathrm{G}$, the precise antiviral activity of the $\mathrm{A} 3$ proteins remains to be elucidated. Human $\mathrm{A} 3 \mathrm{~F}$ was also reported to have anti-HIV-1 activity and susceptibility to HIV-1 Vif (Liddament et al., 2004; Wiegand et al., 2004; Zheng et al., 2004). In contrast, Miyagi et al. (2010) suggested that the antiviral activity of endogenous level of human $\mathrm{A} 3 \mathrm{~F}$ was negligible as compared to the activity of A3G. It is known that human A3DE and A3F, in addition to $\mathrm{A} 3 \mathrm{G}$, are also sensitive to counteraction by HIV-1 Vif (Goila-Gaur and Strebel, 2008). As seen in humans, the RM genome also encodes seven A3 members (Schmitt et al., 2011). Virgen and Hatziioannou (2007) investigated the susceptibility of HIV-1 to each RM A3 family member and showed that A3B, $\mathrm{A} 3 \mathrm{~F}, \mathrm{~A} 3 \mathrm{G}$, and $\mathrm{A} 3 \mathrm{H}$ had the ability to restrict HIV-1 and were resistant to HIV-1 Vif activity. It should be noted that Vif-A3G interaction shows species specificity (Mariani et al., 2003). HIV1 Vif is able to counteract A3G from humans but not from RM and AGM (Zennou and Bieniasz, 2006; Virgen and Hatziioannou, 2007). Conversely, SIVagm Vif is effective against A3G from AGM and RM, but unable to antagonize A3G from human and chimpanzee (Mariani et al., 2003). SIVmac Vif efficiently counteracts A3G from human, chimpanzee, AGM, and RM (Mariani et al., 2003). Are there any polymorphisms in the $A 3$ family? In case of humans, a polymorphism in $A 3 B$ deletion was reported (Kidd et al., 2007). In RMs, a polymorphism in A3DE was observed and was reported to affect the antiviral activity (Virgen and Hatziioannou, 2007). How can we obtain HIV-1 with the ability to overcome macaque A3s? Many efforts have been made to evade from the restriction by the macaque A3 family. Schrofelbauer et al. (2006) showed that mutations of HIV-1 Vif at positions 14-17 from DRMR into SEMQ allowed HIV-1 Vif interaction with A3G from RM. However, this HIV-1 Vif harboring SEMQ remained susceptible to A3B, A3F, and A3H from RM (Virgen and Hatziioannou, 2007), suggesting that the introduction of this sequence 
in HIV-1 Vif was not sufficient for evading from A3s other than A3G. Besides, since the replication of HIV-1 in OWM cells was suppressed, at least at two steps (early and late stages of HIV-1 lifecycle), it is reasonable to speculate that just a modification of $v$ if is insufficient for HIV-1 to overcome the restriction in various OWM cells.

\section{BONE MARROW STROMAL ANTIGEN 2}

It had been observed that the production of $v p u$-deficient HIV1 in certain cell lines was severely diminished (Klimkait et al., 1990; Sakai et al., 1995). Specifically, while permissive cells, such as HEK293T and HT1080 cells, allowed comparative levels of virion production, non-permissive cells, such as Jurkat and HeLa cells, decreased the amount of virion production in the absence of $v p u$. It was also reported that interferon (IFN) treatment led to phenotype switch from permissive to non-permissive (Neil et al., 2007). Thus, the existence of unknown IFN-inducible, Vpusensitive cellular factors, was predicted. In 2008, bone marrow stromal antigen 2 (BST-2), also known as tetherin, CD317, and HM1.24, was identified by two independent groups (Neil et al., 2008; Van Damme et al., 2008). BST-2 is a type 2 integral membrane protein, with the $\mathrm{N}$-terminus located in the cytoplasm, one membrane-spanning domain, and a C-terminus modified by the addition of a glycosyl-phosphatidylinositol (GPI) anchor (Kupzig et al., 2003). Erikson et al. (2011) analyzed the expression profile of BST-2 in vivo and demonstrated that BST-2 was expressed in various tissues, especially spleen and alimentary system. They also showed that among PBMCs, monocytes express high levels of BST-2 as compared to T and B cells. Furthermore, like tripartite motif-containing protein 5 (TRIM $5 \alpha$ ), hominid BST-2, but not other primate BST-2, has been recently reported to function as an innate sensor, leading to the transforming growth factor $\beta$ activated kinase-1 (TAK1)-dependent activation of NFKB and subsequent production of pro-inflammatory cytokines (Galao et al., 2012). Cocka and Bates (2012) recently showed that human BST2 gene expressed alternative splice isoforms that led to different antiviral activity as well as sensing activity from the wild-type one. To overcome BST-2-mediated restriction, HIV-1 downregulates BST-2 from the cell surface by expressing Vpu protein, a viral protein absent in most of the SIVsm/HIV-2 lineage (Neil et al., 2008; Van Damme et al., 2008). On the other hand, HIV-2 utilizes Env protein as an antagonist for human BST-2 (Le Tortorec and Neil, 2009). In the case of SIVmac, Nef protein confers the ability to overcome BST-2-mediated restriction in RM cells (Jia et al., 2009; Sauter etal., 2009; Zhang et al., 2009). It is also reported that Env protein of SIVtan [SIV from Tantalus monkeys (Chlorocebus tantalus)] was effective against BST-2 from human and RM (Gupta et al., 2009). It should be noted that the antagonistic activity of these viral proteins against BST-2 is thought to function in a species-specific manner. While Vpu from the HIV-1 group $\mathrm{M}$ is able to counteract human and chimpanzee BST-2, most of these Vpus are ineffective against BST-2 from RM and AGM (McNatt et al., 2009; Sauter et al., 2009). In contrast, Nef from SIVmac is effective for BST-2 from RM and SM but ineffective for BST2 from human (Jia et al., 2009). This characteristic resistance of human BST-2 to SIV Nef was proven to have an association with the deletion in human BST-2 of 5 amino acid residues, to which
SIV Nef binds (Jia et al., 2009; Zhang et al., 2009). Although most SIVsm/HIV-2 lineage does not encode $v p u$ gene, SIVcpz, SIVgor [SIV from gorillas (Gorilla gorilla gorilla)], SIVgsn [SIV from greater spot-nosed guenons (Cercopithecus nictitans)], SIVmon [SIV from mona monkeys (Cercopithecus mona)], SIVmus [SIV from moustached monkey (Cercopithecus cephus)], and SIVden [SIV from Dent's mona monkey (Cercopithecus denti)] were shown to harbor the $v p u$ gene (Courgnaud etal., 2003; Dazza et al., 2005). Recently, Sauter et al. (2009) demonstrated that Vpus from SIVgsn and SIVden potently counteracted the BST-2 from RM. Moreover, Shingai et al. (2011) showed that Vpu from SHIV DH12 $_{1}$ potently counteracted BST-2 from RM. It is therefore possible that the exchange of present HIV-1 $1_{\mathrm{NL} 4-3}$-derived-Vpu with these Vpus might lead to efficient evasion from the BST-2-mediated restriction in macaque cells. It was reported that a nef-deleted SIVmac239 inoculated to RM became pathogenic after in vivo passage (Alexander et al., 2003; Serra-Moreno et al., 2011). Serra-Moreno et al. (2011) showed that the nef-deleted SIVmac239 gained the ability to antagonize BST-2 by utilizing its Env gp41 as a consequence of adaptive mutations in the env gene. In addition, Vpu from the less pathogenic $\mathrm{HIV}-1$ group $\mathrm{O}$ was reported to lose antiBST-2 activity (Sauter et al., 2009). It was shown that SHIV DH12 lacking intact $\mathrm{Vpu}$ inefficiently replicated in vivo as compared to the wild-type virus (Shingai et al., 2011). These findings indicate the importance of evasion from BST-2-mediated restriction for lentiviral pathogenesis in vivo. Although detailed genetic information is limited, the BST-2 gene is reported to be polymorphic at least in RM (McNatt et al., 2009). Therefore, when using macaques for HIV-1 research, we should also appreciate the polymorphisms in BST-2 gene.

\section{SAMHD1}

It has long been observed that HIV-1 replication in myeloid linage cells, such as macrophages and dendritic cells (DCs) was impaired and the expression of HIV-2/SIV Vpx in trans was shown to rescue this inhibition (Goujon et al., 2007, 2008; Kaushik et al., 2009). The sterile alpha motif (SAM) and histidine/aspartic acid (HD) domain containing protein 1 (SAMHD1) was identified as an HIV-1 restriction factor in myeloid cells that were degraded by the HIV-2/SIV Vpx protein (Hrecka et al., 2011; Laguette etal., 2011). SAMHD1 was reported to restrict HIV1 replication in resting $\mathrm{CD}^{+}{ }^{+} \mathrm{T}$ cells as well (Baldauf et al., 2012; Descours et al., 2012). Historically, SAMHD1 is shown to be associated with the Aicardi-Goutières autoimmune-mediated neurodevelopmental syndrome. Patients having a mutation in SAMHD1 gene would have symptoms of abnormal immune activation likely due to the excessive production of IFN $\alpha$ (Crow and Rehwinkel, 2009; Rice etal., 2009). Since SAMHD1 functions as a deoxyguanosine triphosphate (dGTP)-regulated deoxynucleoside triphosphate (dNTP) triphosphohydrolase (Powell et al., 2011), it exerts its anti-HIV-1 activity via the depletion of dNTP pools in virus-infected cells, leading to the inhibition of the reverse transcription (Lahouassa et al., 2012). The fact that SAMHD1-deficient CD $14^{+}$monocytes efficiently permit HIV-1 replication supports this notion (Berger et al., 2011). It is noteworthy that SAMHD1 exerts its antiviral activity against various retroviruses ranging from alpha, beta and gamma retrovirus, 
except for prototype foamy virus and Human T cell leukemia virus type I (HTLV-1; Gramberg et al., 2013). As described above, the SAMHD1-mediated restriction would be counteracted by HIV-2/SIV Vpx. Hofmann et al. (2012) showed that Vpx recruits SAMHD1 to a cullin4 A-RING E3 ubiquitin ligase, leading to proteasomal degradation. The importance of Vpx in vivo was based on the fact that the replication of $v p x$-deleted SIV in monkeys was significantly weaker than that in wild-type SIV (Gibbs et al., 1995; Hirsch et al., 1998; Belshan et al., 2012). However, vpx-deleted SIV still had the ability to induce simian AIDS in macaques, suggesting a limited role of SAMHD1-mediated restriction in SIV pathogenesis (Gibbs et al., 1995). It is of note that while HIV-2 as well as most of SIV linage such as SIVmac encodes $v p x$, HIV1 as well as some SIV lineage such as SIVcpz and SIVgor does not encode $v p x$ in its genome. Similar to the relationship between A3G and Vif, SAMHD1 is also antagonized by viral proteins in a species-specific manner. For instance, Vpxs from SIVmac and SIVsm are effective against SAMHD1 from human, OWMs, and NWMs (Laguette et al., 2012), while those from SIVrcm [SIV from red-capped mangabey (Cercocebus torquatus)] or SIVmnd [SIV from mandrill (Mandrillus sphinx)] are effective against SAMHD1 from OWMs and NWMs but not from humans (Lim et al., 2012). Lim et al. (2012) also found that Vpr from some SIV lineage, such as SIVdeb [SIV from De Brazza's monkey (Cercopithecus neglectus)], SIVmus, and a part of SIVagm (SIV from AGM), has the potency of degrading SAMHD1 from RM and AGM. It would be of great interest to introduce these vprs into HIV-1mt and examine whether this modification would enhance the viral replication in myeloid linage cells from macaques.

\section{TRIM5}

It was demonstrated that the replication of HIV-1 in OWMs cells was severely abolished before reverse transcription (Besnier et al., 2002; Cowan etal., 2002; Munk etal., 2002). An experiment using interspecies heterokaryons between OWM and human cells suggested the existence of an inhibitory factor in OWM cells (Munk et al., 2002). Stremlau et al. (2004) by screening the RM cDNA library, successfully identified TRIM5 $\alpha$ as a restriction factor in RM cells that confer permissive cells resistance to HIV-1 infection. They also demonstrated that RM TRIM5 $\alpha$, but not human TRIM5 $\alpha$, could restrict HIV-1 infection. On the other hand, human TRIM5 $\alpha$ potently restricts the N-tropic murine leukemia virus (N-MLV) as well as the equine infectious anemia virus (EIAV) but not B-tropic murine leukemia virus (B-MLV; Hatziioannou et al., 2004; Keckesova et al., 2004; Perron etal., 2004; Yap etal., 2004), indicating the importance of TRIM $5 \alpha$ as a host factor restricting the cross-species transmission of retroviruses. TRIM5 $\alpha$ is ubiquitously expressed and consists of a RING domain, a B-box domain, a coiled coil domain, and a PRYSPRY (B30.2) domain (Reymond et al., 2001). The characteristic PRYSPRY domain recognizes the capsid of incoming retroviruses, leading to the restriction of the infection at the postentry step. This domain is also responsible for the species-specific function of TRIM5 $\alpha$ (Nakayama and Shioda, 2010). It was shown that TRIM5 $\alpha$ was IFN-inducible and that IFN treatment of cells led to the augmentation of antiviral activity (Asaoka et al., 2005; Sakuma et al., 2007). An additional role of TRIM5 $\alpha$ as a pattern recognition receptor was recently identified (Pertel et al., 2011). TRIM5 $\alpha$ binds to the incoming viral capsid and then activates its E3 ligase activity, together with the UBC13-UEV1A enzyme complex, resulting in the synthesis of free ubiquitin chains. The chains stimulate TAK1 phosphorylation and the expression of NF- $\mathrm{B}$ (nuclear factor kappa-light-chain-enhancer of activated $B$ cells)- and MPK (mitogen-activated protein kinase)-responsive genes, leading to an antiviral state (De Silva and $\mathrm{Wu}, 2011$ ). Among the restriction factors discussed here, TRIM5 gene might be most polymorphic in primates. At what degree does this polymorphism in TRIM5 gene affect the susceptibility to retroviral infection? A length polymorphism in TRIM5 $\alpha$, in which the TFP residues from position 339 to 341 of TRIM5 $\alpha$ were replaced with a single glutamine (Q), was identified in some RM individuals (Newman et al., 2006). This TFP/Q polymorphism affects the anti-lentiviral activity of RM TRIM5 $\alpha$ against SIVsmE543-3 and SIVsmE041 but not against SIVmac (Kirmaier et al., 2010). Similarly, this polymorphism in RM TRIM5 $\alpha$ is associated with the different antiviral activity against HIV-2 (Kono et al., 2008).

Although most cell lines from NWMs were susceptible to VSV-G pseudotyped HIV-1, cell lines from owl monkey (Aotus trivirgatus) exceptionally showed high resistance to infection by HIV-1 (Hofmann et al., 1999). As the reason for this discrepancy, Sayah et al. (2004) successfully identified TRIM5-Cyclophilin A (CypA) chimeric protein (referred to as TRIMCyp) in owl monkey, which was derived from LINE-1-mediated retrotransposition of CypA cDNA into the region between TRIM5 exons 7 and 8 . In the case of OWMs, the higher susceptibility of PM to HIV-1 infection was, at least in part, explained by the fact that PM exclusively have the TRIMCyp genotype instead of TRIM5 $\alpha$ (Liao et al., 2007; Brennan et al., 2008; Virgen et al., 2008). Differently from owl monkey TRIMCyp, the TRIMCyp of PM was a consequence of a retrotransposition of the CypA sequence in the $3^{\prime}$ untranslated region (UTR) of the TRIM5 gene, together with a single nucleotide polymorphism (SNP) at the exon 7 splice acceptor site. This SNP at the splice acceptor site leads to skipping exons 7 and 8 encoding the PRYSPRY domain and splicing to the inserted CypA gene. In addition to PM, it is reported so far that RM and CM also possess TRIMCyp in their genome (Brennan et al., 2008; Newman et al., 2008; Wilson et al., 2008). Interestingly, RM has geographic deviation in the frequency of TRIMCyp, depending on the country of origin (Wilson et al., 2008). It is reported that Indian RM possessed TRIMCyp more frequently than Chinese RM (Wilson et al., 2008; De Groot et al., 2011). We recently reported that CM also showed divergent frequency of TRIMCyp depending on their country of origin (Saito et al., 2012b). The frequency of TRIMCyp in Filipino CM was significantly higher than that in Malaysian and Indonesian CM. We demonstrated that wild-caught CM also had a geographic deviation in the frequency of TRIMCyp as seen in captive CM (Saito et al., 2012a). Consistently, Dietrich et al. (2011) reported that the frequency of TRIMCyp in Filipino CM was higher than those in Indonesian and Indochina CM. It was shown that Mauritian CM, a population thought to be derived from Indonesian CM, seemed not to possess TRIMCyp, probably due to the founder effects at the time of introduction by human (Dietrich et al., 2011; Berry et al., 2012). Since TRIM5 $\alpha$ is expected to act as homomultimer (Mische et al., 2005; Perez-Caballero et al., 
2005), heterologous expression of TRIM5 $\alpha$ in combination with TRIM5 isoforms other than TRIM5 $\alpha$ reportedly led to a dominant negative effect on the TRIM5 $\alpha$ antiviral activity (Berthoux et al., 2005; Maegawa et al., 2008). Interestingly, it was reported that RM heterozygous for TRIM5 $\alpha$ and TRIMCyp showed higher resistance to repeated intrarectal challenge of SIVsmE660 as compared to RM homozygous for TRIM5 $\alpha$ or TRIMCyp (Reynolds et al., 2011). Since RM TRIMCyp could restrict SIVsm but not SIVmac (Kirmaier etal., 2010), it is reasonable to assume that the combination of TRIM5 $\alpha$ and TRIMCyp may function more efficiently as antiviral factors against SIVsm. We will further discuss the impact of TRIM5 polymorphism on the viral replication in the latter chapter. In summary, since TRIM5 genotype would greatly influence the susceptibility to lentiviruses, the correlation between polymorphism of TRIM5 gene in macaques and outcomes should be carefully evaluated.

\section{UNIDENTIFIED RESTRICTION FACTORS}

Viral infection usually stimulates cellular factors through pattern recognition receptors, such as Toll-like receptor (TLRs) and RIGI-like receptors, expressed on many type of cells, leading to the induction of IFN production (Bowie and Unterholzner, 2008). In particular, type I IFN, which include IFN- $\alpha$ and IFN- $\beta$, puts a switch on the IFN-stimulated gene 15 (ISG15), leading to a cascade of antiviral status (Zhao et al., 2013). The expression levels of the restriction factors described above are reported to increase via IFN stimulation (Asaoka et al., 2005; Tanaka et al., 2006; Neil et al., 2007; Sakuma et al., 2007). Lately, Bitzegeio et al. (2013) have demonstrated that HIV-1-based chimeric viruses, engineered to overcome SAMHD1 or BST-2 as well as A3 and TRIM5 from PM, are still severely restricted in IFN-treated PM PBMCs. They have also demonstrated that the replication of SIVmac in IFN-treated human PBMCs is greatly suppressed, and vice versa. This finding strongly suggests the existence of unidentified, IFN-inducible restriction factors in each species. Therefore, it is also necessary to continue exploring such unidentified cellular factors.

\section{CONSTRUCTION OF MACAOUE-TROPIC HIV-1}

In virtue of the detailed understanding of the molecular relationship between antiviral host factors and viral antagonists (summarized in Tables 1 and 2), it became possible to create a macaque-tropic HIV-1 (HIV-1mt) with the ability to replicate in OWM cells. In 2006, two independent groups succeeded in the construction of an HIV-1mt that contains partial SIVderived sequences on the HIV-1 $1_{\mathrm{NL} 4-3}$ backbone. Hatziioannou et al. (2006) constructed HIV-1mt that contains the entire Gag$\mathrm{CA}$ and vif from SIVmac in order to evade from TRIM $5 \alpha$ - and A3G-mediated restriction, respectively. This HIV-1mt, which contains approximately $88 \%$ of HIV-1-derived sequence, was shown to efficiently replicate in RM PBLs. In parallel with that study, Kamada et al. (2006) constructed HIV-1mt named NLDT5R in which the sequence of CypA binding loop [the loops of $\alpha$-helices 4 and 5 (L4/5)] in Gag-CA and entire vif gene were replaced with those from SIVmac239. NL-DT5R, in which approximately $93 \%$ of its sequence was derived from HIV-1, was shown to replicate in a CM T cell line (HSC-F cells) as well as
Table 1 | Antiviral host factors and antagonism by lentiviral proteins.

\begin{tabular}{lll}
\hline Antiviral host factors & Antagonized by & NOT antagonized by \\
\hline Human APOBEC3G & HIV-1 Vif & SIVagm Vif \\
& SIVmac Vif & \\
RM APOBEC3G & SIVmac Vif & HIV-1 Vif \\
& SIVagm Vif &
\end{tabular}

$\begin{array}{lll}\text { Human BST-2 } & \text { HIV-1 Vpu } & \text { HIV-1 Nef } \\ \text { RM BST-2 } & \text { HIV-2 Env } & \text { SIVmac Nef } \\ & \text { SIVgsn Vpu } & \text { HIV-1 Vpu* } \\ & \text { SIVden Vpu } & \\ & \text { SIVmac Nef } & \\ \text { Human SAMHD1 } & & \\ & \text { SIVdeb Vpr } & \text { HIV-1 Vpr } \\ & \text { SIVmus Vpr } & \text { SIVmac Vpr } \\ & \text { SIVmac Vpx } & \text { SIVrcm Vpx } \\ & \text { HIV-2 Vpx } & \text { SIVmnd Vpx } \\ \text { RM SAMHD1 } & \text { SIVdeb Vpr } & \text { HIV-1 Vpr } \\ & \text { SIVmus Vpr } & \text { SIVmac Vpr } \\ & \text { SIVagm Vpr } & \text { SIVrcm Vpr } \\ & \text { SIVmac Vpx } & \\ & \text { HIV-2 Vpx } * & \\ & \text { SIVrcm Vpx } & \\ & \text { SIVmnd Vpx } & \end{array}$

Summary of findings about APOBEC3G-Vif interaction (Sheehy etal., 2002; Kao et al., 2003; Mariani et al., 2003; Zennou and Bieniasz, 2006; Virgen and Hatziioannou, 2007), BST-2-Vpu, Nef, and Env interaction (Neil etal., 2008; Van Damme etal., 2008; Jia etal., 2009; Le Tortorec and Neil, 2009; Sauter etal., 2009; Zhang etal., 2009; Serra-Moreno etal., 2011), and SAMHD1-Vpx and Vpr interaction (Hrecka etal., 2011; Laguette etal., 2011, 2012; Lim etal., 2012). "Vpus from some HIV-1 strains such as HIV-1 DH12 are able to antagonize RM BST-2. * *Vpss from some HIV-2 strains are ineffective in antagonizing RM SAMHD1.

Table 2 | Species-specific restriction of lentiviruses by primate TRIM5 proteins.

\begin{tabular}{llll}
\hline \multirow{2}{*}{ TRIM5 alleles } & \multicolumn{3}{c}{ Restrictive against: } \\
\cline { 2 - 4 } & HIV-1 & HIV-1mt MN4Rh-3 & SIVmac239 \\
\hline Human TRIM5 $\alpha$ & - & - & - \\
RM TRIM5 $\alpha$ (TFP) & + & + & - \\
RM TRIM5 $\alpha$ (Q) & + & + & - \\
CM TRIM5 $\alpha$ & + & + & - \\
RM TRIMCyp & - & - & - \\
PM TRIMCyp & - & - & - \\
CM TRIMCyp (DK) & + & - & - \\
CM TRIMCyp (NE) & - & - & - \\
\hline
\end{tabular}

Summary of findings about interactions between each TRIM5 allele and lentiviruses (Stremlau etal., 2004; Newman etal., 2006; Liao etal., 2007; Brennan etal., 2008; Virgen etal., 2008; Dietrich etal., 2011; Saito etal., 2012b). "+" denotes restrictive, while "-" denotes not restrictive against each lentivirus, respectively. 
$\mathrm{CD}^{+}$cell-depleted PM PBMCs but hardly in $\mathrm{CD} 8^{+}$cell-depleted RM PBMCs. Subsequently, Igarashi et al. (2007) investigated the replication capability of NL-DT5R in PM and found that this prototypic HIV-1mt was able to induce acute viremia up to around $1 \times 10^{4}$ copies $/ \mathrm{mL}$. Thereafter, in order to enhance the viral replication, we further modified the sequence of NL-DT5Rbased HIV-1mt by 2 different approaches. First, we performed a long-term adaptation experiment in CM T cell lines to induce adaptive mutation in its genome. As a consequence of adaptation, several nucleotide substitutions were identified (see Figure 1, orange arrows in MN4-5 and MN4-5S). The functional significance of each mutation was molecularly evaluated (Nomaguchi et al., 2013a). Second, we introduced the $\alpha$-helices 6 and 7 (L6/7) in addition to L4/5 of Gag-CA into MN4-5, resulting in MN4-5S. As shown in Figure 2, this substitution enhanced the viral replication in vitro (Kuroishi et al., 2009) and in vivo (Saito et al., 2011). We next constructed a new HIV-1mt named MN4Rh-3 carrying the Q110D substitution in Gag-CA. This HIV-1mt exhibited further enhanced growth property specifically in macaque cells but impaired replication in human cells (Nomaguchi et al., 2013b). We also examined the replicative property of MN4Rh-3 in CM (Saito et al., 2013). In accordance with in vitro data (Nomaguchi et al., 2013b), MN4Rh-3 induced higher viremia on average up to 50 times as compared to MN4-5S (Figure 2). Notably, TRIMCyp homozygotes were highly permissive to MN4Rh-3 infection, while the replication of MN4Rh-3 in TRIM5 homozygotes was strongly suppressed. We also observed that CM heterologous for TRIM5 $\alpha$ and TRIMCyp showed similar anti-HIV-1 activity with TRIMCyp homozygotes (Saito et al., 2013). These findings indicated that MN4Rh-3 enhanced the replicative capability in CM having TRIMCyp, but was still unable to overcome TRIM5 $\alpha$-mediated restriction. It should be noted that the sequence of most TRIMCyp encoded in CM are different from those in RM and PM. It was once thought that CM exclusively possessed TRIMCyp in which the amino acid residues at positions 369 (Cyp66) and 446 (Cyp143) were aspartic acid (D) and lysine (K) [denoted as the TRIMCyp (DK)], respectively, while PM and RM had TRIMCyp in which the amino acids at the corresponding positions were asparagine $(\mathrm{N})$

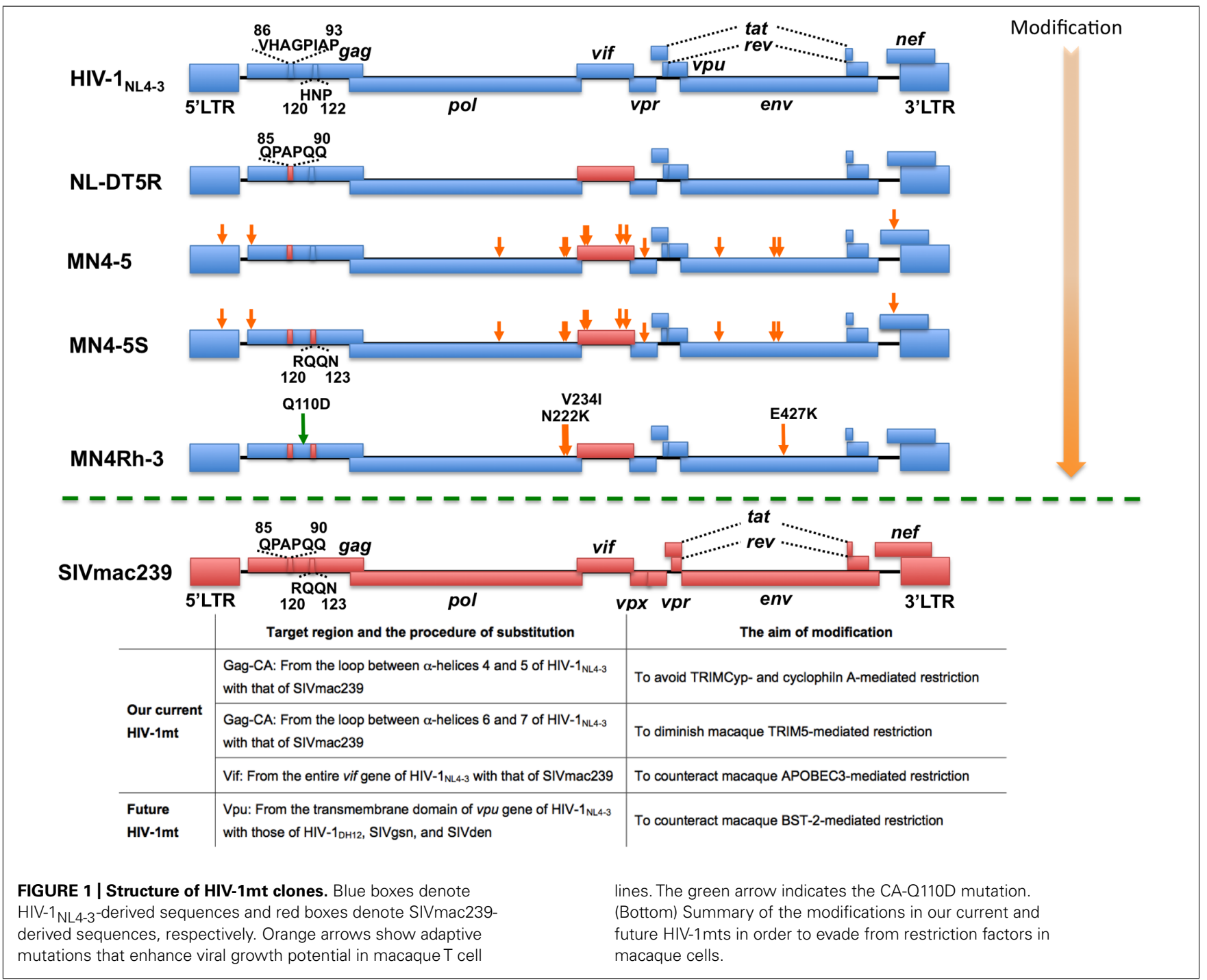




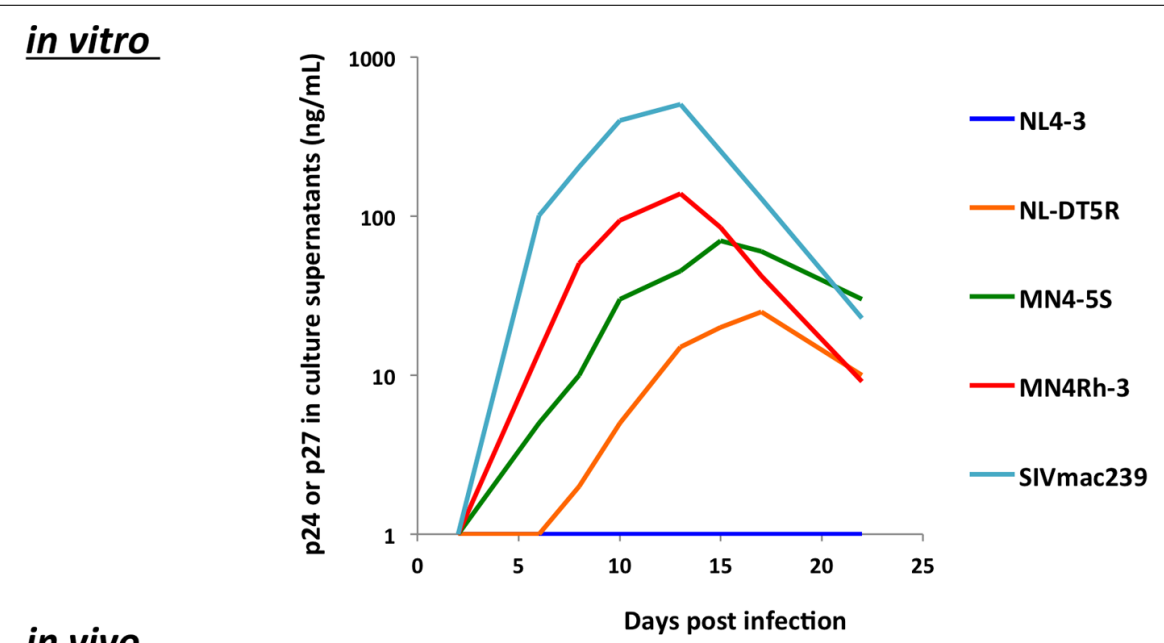

in vivo
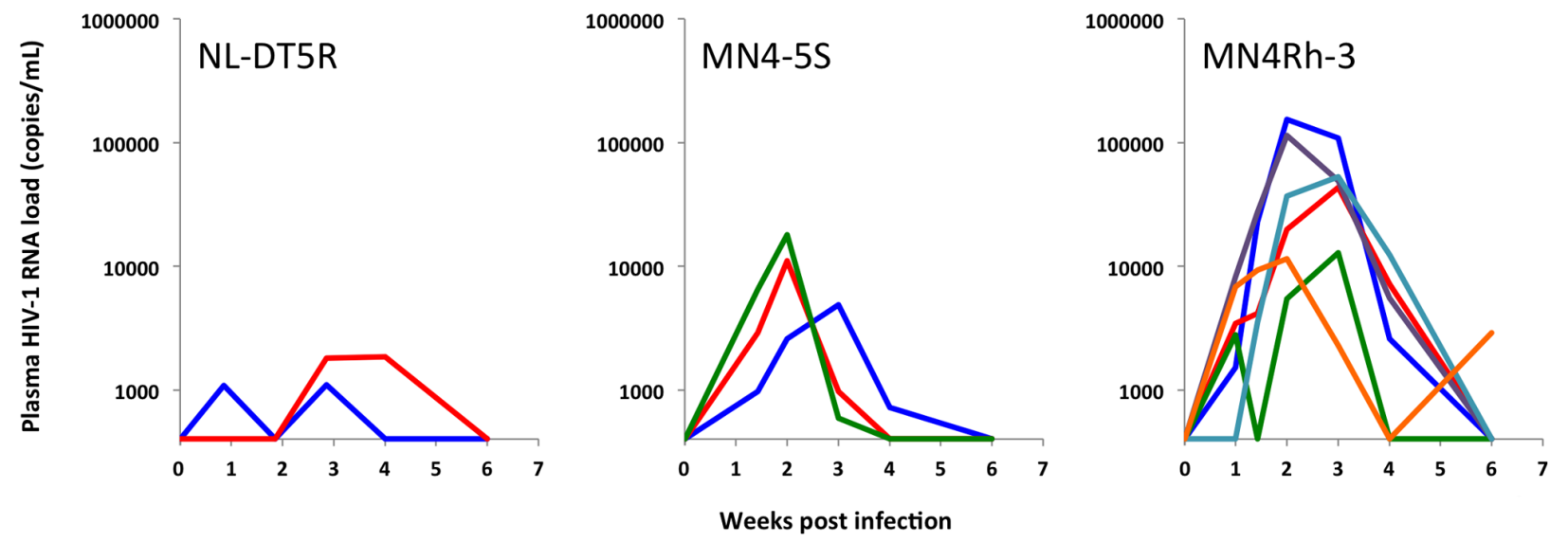

FIGURE 2 | Serial modifications of the viral genome lead to an enhanced viral replication in vitro and in vivo. (Top) $C D 8^{+} \mathrm{T}$ cell-depleted peripheral

with each HIV-1 mt. The representative result of viral replication kinetics was mononuclear blood cells from CMs homozygous for TRIMCyp were infected shown. (Bottom) CM having TRIMCyp were infected with each HIV-1m intravenously. Plasma viral RNA loads in each monkey are shown.

and glutamic acid (E) [denoted as the TRIMCyp (NE); Brennan et al., 2008; Ylinen et al., 2010], respectively. However, others and we recently revealed that CM possessed TRIMCyp (NE) as well as TRIMCyp (DK) in spite of the low frequency of TRIMCyp (NE) haplotype in CM population (Dietrich et al., 2011; Saito et al., 2012a,b). Strikingly, others and we reported that TRIMCyp (DK) and TRIMCyp (NE) exhibit different anti-lentiviral activity. It is well established that the TRIMCyp (DK) efficiently restricts HIV-1 but weakly restricts HIV-2 (Saito et al., 2012b). On the other hand, the TRIMCyp (NE) fails to restrict HIV-1 but efficiently restrict HIV-2 (Wilson et al., 2008). It was also shown that both haplotypes hardly restricted SIVmac239 replication. These results indicate that the sequence variations in CypA greatly affect the spectrum of their anti-HIV-1 activity. However, how does TRIMCyp (DK) exert its anti-HIV-1 activity? Actually, TRIMCyp (DK) is expected to bind the L4/5 in Gag-CA. Moreover, the treatment of the target cells with cyclosporin A, an inhibitor against CypA, or the introduction of amino acid changes in this loop of the viral genome relieved the inhibitory effect by TRIMCyp (DK; Ylinen et al., 2010). Therefore, when we use CM homozygous for TRIMCyp (DK), it is necessary to modify the loop in order to evade restriction. In fact, we have used HIV-1mts in which the L4/5 in Gag-CA were replaced with the corresponding sequence of SIVmac239 (Kamada et al., 2006). In contrast, those research groups that used PM did not need to modify this region. Hatziioannou et al. (2009) have successfully constructed an HIV-1mt that induced persistent viremia in PM with modification of only vif and env gene. Similarly, Thippeshappa et al. (2011) also constructed an HIV-1mt named HSIV-vif that encoded vif gene from pathogenic PM-adapted SIVmne027. This HSIV-vif was shown to persistently replicate in PM but was unable to induce pathogenicity in animals. Overall, further understanding of the host-virus relationship would permit us to construct pathogenic HIV-1mt in future studies.

\section{CONCLUSIONS AND FUTURE DIRECTIONS}

Most HIV-1mts were constructed with the aim of evading from TRIM5 and APOBEC3-mediated restriction. In the future research, as discussed above, we should also focus on other factors such as BST-2 and SAMHD1. It will be promising to modify viral genome in order to overcome these restrictions. We expect that 
such procedure will lead to the construction of a new HIV-1mt with the ability to infect various macaques persistently.

Also, as discussed in the "History of HIV-1 animal models" chapter, an R5-tropic virus would be promising to reproduce the transmission, latency, and pathogenicity of HIV-1 in macaques. In the future study, the construction of an R5-tropic virus on the HIV-1mt backbone would encourage us to examine the antiviral agents, vaccines, and microbicides in macaques. Moreover, HIV$1 \mathrm{mt}$ that robustly replicate and induce pathogenicity in monkeys will make feasible to investigate the role and mechanism of HIV-1

\section{REFERENCES}

Agy, M. B., Frumkin, L. R., Corey, L., Coombs, R. W., Wolinsky, S. M., Koehler, J., et al. (1992). Infection of Macaca nemestrina by human immunodeficiency virus type- 1 . Science 257, 103-106. doi: 10.1126/science. 1621083

Agy, M. B., Schmidt, A., Florey, M. J., Kennedy, B. J., Schaefer, G., Katze, M. G., et al. (1997). Serial in vivo passage of HIV-1 infection in Macaca nemestrina. Virology 238, 336-343. doi: 10.1006/viro.1997.8832

Akiyama, H., Ishimatsu, M., Miura, T., Hayami, M., and Ido, E. (2008). Construction and infection of a new simian/human immunodeficiency chimeric virus (SHIV) containing the integrase gene of the human immunodeficiency virus type 1 genome and analysis of its adaptation to monkey cells. Microbes Infect. 10, 531-539. doi: 10.1016/j.micinf.2008.02.001

Alexander, L., Illyinskii, P. O., Lang, S. M., Means, R. E., Lifson, J., Mansfield, K., et al. (2003). Determinants of increased replicative capacity of serially passaged simian immunodeficiency virus with nef deleted in rhesus monkeys. J. Virol. 77, 68236835. doi: 10.1128/JVI.77.12.68236835.2003

Alter, H. J., Eichberg, J. W., Masur, H., Saxinger, W. C., Gallo, R., Macher, A. M., et al. (1984). Transmission of HTLV-III infection from human plasma to chimpanzees: an animal model for AIDS. Science 226, 549552. doi: 10.1126/science.6093251

Amara, R. R., Villinger, F., Altman, J. D., Lydy, S. L., O’Neil, S. P., Staprans, S. I., et al. (2001). Control of a mucosal challenge and prevention of AIDS by a multiprotein DNA/MVA vaccine. Science 292, 69-74. doi: 10.1126/science. 1058915

Ambrose, Z., Boltz, V., Palmer, S., Coffin, J. M., Hughes, S. H., and Kewalramani, V. N. (2004). In vitro characterization of a simian immunodeficiency virushuman immunodeficiency virus (HIV) chimera expressing HIV type 1 reverse transcriptase to study antiviral resistance in pigtail macaques. J. Virol. 78, 1355313561. doi: 10.1128/JVI.78.24.1355313561.2004

Asaoka, K., Ikeda, K., Hishinuma, T., Horie-Inoue, K., Takeda, S., and Inoue, S. (2005). A retrovirus restriction factor TRIM5alpha is transcriptionally regulated by interferons. Biochem. Biophys. Res. Commun. 338, 1950-1956. doi: 10.1016/j.bbrc.2005.10.173

Atchison, R. E., Gosling, J., Monteclaro, F. S., Franci, C., Digilio, L., Charo, I. F., et al. (1996). Multiple extracellular elements of CCR5 and HIV-1 entry: dissociation from response to chemokines. Science 274, 1924-1926. doi: 10.1126/science.274. 5294.1924

Baba, T. W., Liska, V., HofmannLehmann, R., Vlasak, J., Xu, W., Ayehunie, S., et al. (2000). Human neutralizing monoclonal antibodies of the IgG1 subtype protect against mucosal simian-human immunodeficiency virus infection. Nat. Med. 6, 200-206. doi: 10.1038/72309

Baldauf, H. M., Pan, X., Erikson, E., Schmidt, S., Daddacha, W., Burggraf, M., et al. (2012). SAMHD1 restricts HIV-1 infection in resting CD4(+) T cells. Nat. Med. 18, 1682-1687. doi: 10.1038/nm.2964

Barouch, D. H., Santra, S., Kuroda, M. J., Schmitz, J. E., Plishka, R., Buckler-White, A., et al. (2001). Reduction of simian-human immunodeficiency virus $89.6 \mathrm{P}$ viremia in rhesus monkeys by recombinant modified vaccinia virus Ankara vaccination. J. virol. 75, 5151-5158. doi: 10.1128/JVI.75.11. 5151-5158.2001

Belshan, M., Kimata, J. T., Brown, C., Cheng, X., Mcculley, A., Larsen, A., etal. (2012). Vpx is criti$\mathrm{cal}$ for SIVmne infection of pigtail macaques. Retrovirology 9, 32. doi: 10.1186/1742-4690-9-32

Berger, A., Sommer, A. F., Zwarg, J., Hamdorf, M., Welzel, K., Esly, N., et al. (2011). SAMHD1-deficient CD14+ cells from individuals with

accessory genes in the HIV-1 lifecycle, persistence, and pathogenesis. In summary, although the road to the containment of HIV-1 epidemic may be long and steep, we have been moving forward slowly but steadily.

\section{ACKNOWLEDGMENTS}

The authors would like to give special thanks to Atsunori Higashino and Saori Suzuki for helpful suggestions. This work was supported by grants from the Ministry of Health, Labor, and Welfare of Japan.

Aicardi-Goutieres syndrome are highly susceptible to HIV-1 infection. PLoS Pathog. 7:e1002425. doi: 10.1371/journal.ppat.1002425

Berges, B. K., and Rowan, M. R. (2011). The utility of the new generation of humanized mice to study HIV-1 infection: transmission, prevention, pathogenesis, and treatment. Retrovirology 8, 65. doi: 10.1186/17424690-8-65

Berry, N. J., Marzetta, F., Towers, G. J., and Rose, N. J. (2012). Diversity of TRIM5alpha and TRIMCyp sequences in cynomolgus macaques from different geographical origins. Immunogenetics 64, 267-278. doi: 10.1007/s00251-011-0585-x

Berthoux, L., Sebastian, S., Sayah, D. M., and Luban, J. (2005). Disruption of human TRIM5alpha antiviral activity by nonhuman primate orthologues. J. Virol. 79, 78837888. doi: 10.1128/JVI.79.12.78837888.2005

Besnier, C., Takeuchi, Y., and Towers, G. (2002). Restriction of lentivirus in monkeys. Proc. Natl. Acad. Sci. U.S.A. 99, 11920-11925. doi: 10.1073/pnas.172384599

Bitzegeio, J., Sampias, M., Bieniasz, P. D., and Hatziioannou, T. (2013). Adaptation to the interferoninduced antiviral state by human and simian immunodeficiency viruses. J. Virol. 87, 3549-3560. doi: 10.1128/JVI.03219-12

Bomsel, M., Tudor, D., Drillet, A. S., Alfsen, A., Ganor, Y. Roger, M. G., et al. (2011). Immunization with HIV-1 gp41 subunit virosomes induces mucosal antibodies protecting nonhuman primates against vaginal SHIV challenges. Immunity 34, 269-280. doi: 10.1016/j.immuni.2011.01.015

Bowie, A. G., and Unterholzner, L. (2008). Viral evasion and subversion of pattern-recognition receptor signaling. Nat. Rev. Immunol. 8, 911-922. doi: 10.1038/nri2436

Brennan, G., Kozyrev, Y., and Hu, S. L. (2008). TRIMCyp expression in Old World primates Macaca nemestrina and Macaca fascicularis. Proc. Natl.
Acad. Sci. U.S.A. 105, 3569-3574. doi: 10.1073/pnas.0709511105

Cafaro, A., Caputo, A., Fracasso, C., Maggiorella, M. T., Goletti, D., Baroncelli, S., et al. (1999). Control of SHIV-89.6P-infection of cynomolgus monkeys by HIV-1 Tat protein vaccine. Nat. Med. 5, 643-650. doi: 10.1038/9488

Cocka, L. J., and Bates, P. (2012). Identification of alternatively translated Tetherin isoforms with differing antiviral and signaling activities. PLoS Pathog. 8:e1002931. doi: 10.1371/journal. ppat.1002931

Cohen, J. (2007). Animal studies. NIH to end chimp breeding for research. Science 316, 1265. doi: 10.1126/science.316.5829.1265

Conticello, S. G., Harris, R. S., and Neuberger, M. S. (2003). The Vif protein of HIV triggers degradation of the human antiretroviral DNA deaminase APOBEC3G. Curr. Biol. 13, 2009-2013. doi: 10.1016/j.cub.2003. 10.034

Courgnaud, V., Abela, B., Pourrut, X., Mpoudi-Ngole, E., Loul, S., Delaporte, E., et al. (2003). Identification of a new simian immunodeficiency virus lineage with a vpu gene present among different cercopithecus monkeys (C. mona, C. cephus, and C. nictitans) from Cameroon. J. Virol. 77, 1252312534. doi: 10.1128/JVI.77.23.1252312534.2003

Cowan, S., Hatziioannou, T., Cunningham, T., Muesing, M. A., Gottlinger, H. G., and Bieniasz, P. D. (2002). Cellular inhibitors with Fvl-like activity restrict human and simian immunodeficiency virus tropism. Proc. Nat. Acad. Sci. U.S.A. 99, 11914-11919. doi: 10.1073/pnas.162299499

Crow, Y. J., and Rehwinkel, J. (2009). Aicardi-Goutieres syndrome and related phenotypes: linking nucleic acid metabolism with autoimmunity. Hum. Mol. Genet. 18, R130-R136. doi: 10.1093/hmg/ddp293

Daniel, M. D., Kirchhoff, F., Czajak, S. C., Sehgal, P. K., and Desrosiers, R. C. (1992). Protective effects of 
a live attenuated SIV vaccine with a deletion in the nef gene. Science 258, 1938-1941. doi: 10.1126/science. 1470917

Daniel, M. D., Letvin, N. L., King, N. W., Kannagi, M., Sehgal, P. K., Hunt, R. D., et al. (1985). Isolation of T-cell tropic HTLV-III-like retrovirus from macaques. Science 228, 1201-1204. doi: 10.1126/science.3159089

Dazza, M. C., Ekwalanga, M., Nende, M., Shamamba, K. B., Bitshi, P., Paraskevis, D., et al. (2005). Characterization of a novel vpu-harboring simian immunodeficiency virus from a Dent's Mona monkey (Cercopithecus mona denti). J. Virol. 79, 8560-8571. doi: 10.1128/JVI.79.13. 8560-8571.2005

De Groot, N. G., Heijmans, C. M. Koopman, G., Verschoor, E. J., Bogers, W. M., and Bontrop, R. E. (2011). TRIM5 allelic polymorphism in macaque species/populations of different geographic origins: its impact on SIV vaccine studies. Tissue Antigens 78, 256-262. doi: 10.1111/j.1399-0039.2011.01768.x

Denton, P. W., Estes, J. D., Sun, Z., Othieno, F. A., Wei, B. L., Wege, A. K., et al. (2008). Antiretroviral preexposure prophylaxis prevents vaginal transmission of HIV-1 in humanized BLT mice. PLoS Med. 5:e16. doi: 10.1371/journal.pmed.0050016

Denton, P. W., Olesen, R., Choudhary, S. K., Archin, N. M., Wahl, A., Swanson, M. D., et al. (2012). Generation of HIV latency in humanized BLT mice. J. Virol. 86, 630-634. doi: 10.1128/JVI.06120-11

Descours, B., Cribier, A., Chable-Bessia, C., Ayinde, D., Rice, G., Crow, Y., et al. (2012). SAMHD1 restricts HIV1 reverse transcription in quiescent CD4(+) T-cells. Retrovirology 9, 87. doi: 10.1186/1742-4690-9-87

De Silva, S., and Wu, L. (2011). TRIM5 acts as more than a retroviral restriction factor. Viruses 3, 1204-1209. doi: 10.3390/v3071204

Dietrich, E. A., Brennan, G., Ferguson, B., Wiseman, R. W., O'Connor, D., and $\mathrm{Hu}, \mathrm{S}$. L. (2011). Variable prevalence and functional diversity of the antiretroviral restriction factor TRIMCyp in Macaca fascicularis. J. Virol. 85, 9956-9963. doi: 10.1128/JVI.00097-11

Erikson, E., Adam, T., Schmidt, S., Lehmann-Koch, J., Over, B., Goffinet, C., et al. (2011). In vivo expression profile of the antiviral restriction factor and tumor-targeting antigen CD317/BST-2/HM1.24/tetherin in humans. Proc. Natl. Acad. Sci. U.S.A. 108, 13688-13693. doi: $10.1073 /$ pnas. 1101684108
Feinberg, M. B., and Moore, J. P. (2002). AIDS vaccine models: challenging challenge viruses. Nat. Med. 8, 207210. doi: 10.1038/nm0302-207

Filice, G., Cereda, P. M., and Varnier, O. E. (1988). Infection of rabbits with human immunodeficiency virus. Nature 335, 366-369. doi: 10.1038/335366a0

Fultz, P. N., Mcclure, H. M., Swenson, R. B., Mcgrath, C. R., Brodie, A. Getchell, J. P., et al. (1986). Persistent infection of chimpanzees with human T-lymphotropic virus type III/lymphadenopathy-associated virus: a potential model for acquired immunodeficiency syndrome. J. Virol. 58, 116-124.

Fultz, P. N., Siegel, R. L., Brodie, A., Mawle, A. C., Stricker, R. B. Swenson, R. B., et al. (1991). Prolonged CD4+ lymphocytopenia and thrombocytopenia in a chimpanzee persistently infected with human immunodeficiency virus type 1 . J. Infect. Dis. 163, 441-447. doi: 10.1093/infdis/163.3.441

Fultz, P. N., Srinivasan, A., Greene, C. R., Butler, D., Swenson, R. B., and Mcclure, H. M. (1987). Superinfection of a chimpanzee with a second strain of human immunodeficiency virus. J. Virol. 61, 4026-4029.

Fultz, P. N., Wei, Q., and Yue, L. (1999). Rectal transmission of human immunodeficiency virus type 1 to chimpanzees. J. Infect. Dis. 179(Suppl. 3), S418-S421. doi: 10.1086/314796

Gabuzda, D. H., Lawrence, K., Langhoff, E., Terwilliger, E., Dorfman, T., Haseltine, W. A., et al. (1992). Role of vif in replication of human immunodeficiency virus type 1 in CD4+ T lymphocytes. J. Virol. 66, 6489-6495. doi: 10.1186/1742-4690-9-93

Galao, R. P., Le Tortorec, A., Pickering, S., Kueck, T., and Neil, S. J. (2012). Innate sensing of HIV-1 assembly by Tetherin induces NFkappaB-dependent proinflammatory responses. Cell Host Microbe 12, 633-644. doi: 10.1016/j.chom.2012. 10.007

Gardner, M. B., and Luciw, P. A. (1989). Animal models of AIDS. FASEB J. 3, 2593-2606. doi: 10.1038/nrmicro2911

Gautam, R., Nishimura, Y., Lee, W. R., Donau, O., Buckler-White, A., Shingai, M., et al. (2012). Pathogenicity and mucosal transmissibility of the R5-tropic simian/human immunodeficiency virus SHIV(AD8) in rhesus macaques: implications for use in vaccine studies. J. Virol. 86, 8516-8526. doi: 10.1128/JVI. 00644-12
Gibbs, J. S., Lackner, A. A., Lang, S. M., Simon, M. A., Sehgal, P. K., Daniel, M. D., etal. (1995). Progression to AIDS in the absence of a gene for vpr or vpx. J. Virol. 69, 2378-2383.

Goila-Gaur, R., and Strebel, K. (2008). HIV-1 Vif, APOBEC, and intrinsic immunity. Retrovirology 5:51. doi: 10.1186/1742-4690-5-51

Goujon, C., Arfi, V., Pertel, T., Luban, J., Lienard, J., Rigal, D., et al. (2008) Characterization of simian immunodeficiency virus SIVSM/human immunodeficiency virus type 2 $\mathrm{Vpx}$ function in human myeloid cells. J. Virol. 82, 12335-12345. doi: 10.1128/JVI.01181-08

Goujon, C., Riviere, L., JarrossonWuilleme, L., Bernaud, J., Rigal, D., Darlix, J. L., et al. (2007) SIVSM/HIV-2 Vpx proteins promote retroviral escape from a proteasome-dependent restriction pathway present in human dendritic cells. Retrovirology 4, 2. doi: 10.1186/1742-4690-4-2

Gramberg, T., Kahle, T., Bloch, N., Wittmann, S., Müllers, E., Daddacha, W., etal. (2013). Restriction of diverse retroviruses by SAMHD1. Retrovirology 10, 26. doi: 10.1186/1742-4690-10-26

Gupta, R. K., Mlcochova, P., PelchenMatthews, A., Petit, S. J., Mattiuzzo, G., Pillay, D., et al. (2009). Simian immunodeficiency virus envelope glycoprotein counteracts tetherin/BST-2/CD317 by intracellular sequestration. Proc. Natl. Acad. Sci. U.S.A. 106, 20889-20894. doi: 10.1073/pnas.0907075106

Harouse, J. M. (1999). Distinct Pathogenic Sequela in Rhesus Macaques Infected with CCR5 or CXCR4 Utilizing SHIVs. Science 284, 816-819. doi: 10.1126/ science.284.5415.816

Hatziioannou, T., Ambrose, Z., Chung, N. P., Piatak, M. Jr., Yuan, F., Trubey, C. M., etal. (2009). A macaque model of HIV-1 infection. Proc. Natl. Acad. Sci. U.S.A. 106, 4425-4429. doi: 10.1073/pnas.0812587106

Hatziioannou, T., Perez-Caballero, D., Yang, A., Cowan, S., and Bieniasz, P. D. (2004). Retrovirus resistance factors Refl and Lv1 are species-specific variants of TRIM5alpha. Proc. Natl. Acad. Sci. U.S.A. 101, 10774-10779. doi: 10.1073/pnas.0402361101

Hatziioannou, T., Princiotta, M., Piatak, M. Jr., Yuan, F., Zhang, F., Lifson, J. D., et al. (2006). Generation of simian-tropic HIV-1 by restriction factor evasion. Science 314, 95. doi: 10.1126/science. 1130994
Hirsch, V. M., Sharkey, M. E., Brown, C. R., Brichacek, B., Goldstein, S., Wakefield, J., et al. (1998). Vpx is required for dissemination and pathogenesis of SIV(SM) PBj: evidence of macrophage-dependent viral amplification. Nat. Med. 4, 1401-1408. doi: 10.1038/3992

Ho, S. H., Shek, L., Gettie, A., Blanchard, J., and Cheng-Mayer, C. (2005). V3 loop-determined coreceptor preference dictates the dynamics of CD4+-T-cell loss in simian-human immunodeficiency virus-infected macaques. J. Virol. 79, 1229612303. doi: 10.1128/JVI.79.19.1229612303.2005

Hofmann, H., Logue, E. C., Bloch, N., Daddacha, W., Polsky, S. B., Schultz, M. L., et al. (2012). The Vpx lentiviral accessory protein targets SAMHD1 for degradation in the nucleus. J. Virol. 86, 12552-12560. doi: 10.1128/JVI.01657-12

Hofmann, W., Schubert, D., LaBonte, J., Munson, L., Gibson, S., Scammell, J., et al. (1999). Species-specific, postentry barriers to primate immunodeficiency virus infection. J. Virol. 73, 10020-10028. doi: 10.1038 /nature 02343

Hrecka, K., Hao, C., Gierszewska, M., Swanson, S. K., Kesik-Brodacka, M., Srivastava, S., et al. (2011). Vpx relieves inhibition of HIV-1 infection of macrophages mediated by the SAMHD1 protein. Nature 474, 658-661. doi: 10.1038/nature10195

Hultquist, J. F., Binka, M., Larue, R. S., Simon, V., and Harris, R. S. (2012). Vif proteins of human and simian immunodeficiency viruses require cellular CBFbeta to degrade APOBEC3 restriction factors. J. Virol. 86, 2874-2877. doi: 10.1128/JVI.06950-11

Humes, D., Emery, S., Laws, E., and Overbaugh, J. (2012). A species-specific amino acid difference in the macaque CD4 receptor restricts replication by global circulating HIV-1 variants representing viruses from recent infection. J. Virol. 86, 12472-12483. doi: 10.1128/JVI. 02176-12

Humes, D., and Overbaugh, J. (2011). Adaptation of subtype a human immunodeficiency virus type 1 envelope to pig-tailed macaque cells. J. Virol. 85, 4409-4420. doi: 10.1128/JVI.02244-10

Igarashi, T., Ami, Y., Yamamoto, H., Shibata, R., Kuwata, T., Mukai, R., etal. (1997). Protection of monkeys vaccinated with vpr- and/or nefdefective simian immunodeficiency virus strain mac/human immunodeficiency virus type 1 chimeric viruses: 
a potential candidate live-attenuated human AIDS vaccine. J. Gen. Virol. 78, 985-989. doi: 10.1186/17424690-4-66

Igarashi, T., Iyengar, R., Byrum, R. A., Buckler-White, A., Dewar, R. L., Buckler, C. E., et al. (2007). Human immunodeficiency virus type 1 derivative with $7 \%$ simian immunodeficiency virus genetic content is able to establish infections in pig-tailed macaques. J. Virol. 81, 11549-11552. doi: 10.1128/JVI.00960-07

Ito, M., Hiramatsu, H., Kobayashi, K., Suzue, K., Kawahata, M., Hioki, K., etal. (2002). NOD/SCID/gamma(c)(null) mouse: an excellent recipient mouse model for engraftment of human cells. Blood 100, 3175-3182. doi: 10.1182/ blood-2001-12-0207

Jager, S., Kim, D. Y., Hultquist, J. F., Shindo, K., Larue, R. S., Kwon, E., et al. (2012). Vif hijacks CBF-beta to degrade APOBEC3G and promote HIV-1 infection. Nature 481, 371375. doi: 10.1038/nature 10693

Jarmuz, A., Chester, A., Bayliss, J., Gisbourne, J., Dunham, I., Scott, J., etal. (2002). An anthropoidspecific locus of orphan $\mathrm{C}$ to $\mathrm{U}$ RNA-editing enzymes on chromosome 22. Genomics 79, 285-296. doi: 10.1006/geno.2002.6718

Jia, B., Serra-Moreno, R., Neidermyer, W., Rahmberg, A., Mackey, J., Fofana, I. B., et al. (2009). Speciesspecific activity of SIV Nef and HIV-1 Vpu in overcoming restriction by tetherin/BST2. PLoS Pathog. 5:e1000429. doi: 10.1371/journal. ppat. 1000429

Johnson, B. K., Stone, G. A., Godec, M. S., Asher, D. M., Gajdusek, D. C., and Gibbs, C. J. Jr. (1993). Long-term observations of human immunodeficiency virus-infected chimpanzees. AIDS Res. Hum. Retroviruses 9, 375-378. doi: 10.1089/aid. 1993.9.375

Kamada, K., Igarashi, T., Martin, M. A., Khamsri, B., Hatcho, K. Yamashita, T., et al. (2006). Generation of HIV-1 derivatives that productively infect macaque monkey lymphoid cells. Proc. Natl. Acad. Sci. U.S.A. 103, 16959-16964. doi: 10.1073/pnas.0608289103

Kao, S., Khan, M. A., Miyagi, E., Plishka, R., Buckler-White, A., and Strebel, K. (2003). The human immunodeficiency virus type 1 Vif protein reduces intracellular expression and inhibits packaging of APOBEC $3 \mathrm{G}$ (CEM15), a cellular inhibitor of virus infectivity. J. Virol. 77, 1139811407. doi: 10.1128/JVI.77.21.1139811407.2003
Kaushik, R., Zhu, X., Stranska, R., Wu, Y., and Stevenson, M. (2009). A cellular restriction dictates the permissivity of nondividing monocytes/macrophages to lentivirus and gammaretrovirus infection. Cell Host Microbe 6, 68-80. doi: 10.1016/j.chom.2009. 05.022

Keckesova, Z., Ylinen, L. M., and Towers, G. J. (2004). The human and African green monkey TRIM5alpha genes encode Ref1 and Lvl retroviral restriction factor activities. Proc. Natl. Acad. Sci. U.S.A. 101, 10780-10785. doi: 10.1073/pnas.0402474101

Kestler, H., Kodama, T., Ringler, D., Marthas, M., Pedersen, N., Lackner, A., et al. (1990). Induction of AIDS in rhesus monkeys by molecularly cloned simian immunodeficiency virus. Science 248, 1109-1112. doi: $10.1126 /$ science. 2160735

Kestler, H. W. III., Ringler, D. J., Mori, K., Panicali, D. L., Sehgal, P. K., Daniel, M. D., et al. (1991). Importance of the nef gene for maintenance of high virus loads and for development of AIDS. Cell 65, 651662. doi: 10.1016/0092-8674(91) 90097-I

Kidd, J. M., Newman, T. L., Tuzun, E., Kaul, R., and Eichler, E. E. (2007). Population stratification of a common APOBEC gene deletion polymorphism. PLoS Genet. 3:e63. doi: 10.1371/journal.pgen. 0030063

Kiepiela, P., Ngumbela, K., Thobakgale, C., Ramduth, D., Honeyborne, I., Moodley, E., et al. (2007). CD8+ T-cell responses to different HIV proteins have discordant associations with viral load. Nat. Med. 13, 46-53. doi: $10.1038 / \mathrm{nm} 1520$

Kirmaier, A., Wu, F., Newman, R. M., Hall, L. R., Morgan, J. S., O'connor S., et al. (2010). TRIM5 suppresses cross-species transmission of a primate immunodeficiency virus and selects for emergence of resistant variants in the new species. PLoS Biol. 8:e1000462. doi: 10.1371/journal.pbio.1000462

Klimkait, T., Strebel, K., Hoggan, M. D., Martin, M. A., and Orenstein J. M. (1990). The human immunodeficiency virus type 1 -specific protein $\mathrm{vpu}$ is required for efficient virus maturation and release. J. Virol. 64, 621-629. doi: 10.1016/S12864579(03)00191-6

Kono, K., Song, H., Shingai, Y., Shioda, T., and Nakayama, E. E. (2008). Comparison of anti-viral activity of rhesus monkey and cynomolgus monkey TRIM5alphas against human immunodeficiency virus type 2 infection. Virology 373, 447-456. doi: 10.1016/j.virol.2007.12.022

Kraus, G., Werner, A., Baier, M. Binniger, D., Ferdinand, F. J., Norley, S., etal. (1989). Isolation of human immunodeficiency virus-related simian immunodeficiency viruses from African green monkeys. Proc. Natl. Acad. Sci. U.S.A. 86, 2892-2896. doi: 10.1073/pnas.86. 8.2892

Kulaga, H., Folks, T., Rutledge, R., Truckenmiller, M. E., Gugel, E. and Kindt, T. J. (1989). Infection of rabbits with human immunodeficiency virus 1 . A small animal model for acquired immunodeficiency syndrome. J. Exp. Med. 169, 321-326. doi: 10.1084/jem. 169.1.321

Kupzig, S., Korolchuk, V., Rollason, R. Sugden, A., Wilde, A., and Banting, G. (2003). Bst-2/HM1.24 is a raft-associated apical membrane protein with an unusual topology. Traffic 4, 694-709. doi: 10.1034/j.16000854.2003.00129.x

Kuroishi, A., Saito, A., Shingai, Y. Shioda, T., Nomaguchi, M., Adachi, A., et al. (2009). Modification of a loop sequence between alphahelices 6 and 7 of virus capsid (CA) protein in a human immunodeficiency virus type 1 (HIV-1) derivative that has simian immunodeficiency virus (SIVmac239) vif and CA alpha-helices 4 and 5 loop improves replication in cynomolgus monkey cells. Retrovirology 6, 70. doi: 10.1186/1742 4690-6-70

Kwak, Y. T., Ivanov, D., Guo, J., Nee, E., and Gaynor, R. B. (1999). Role of the human and murine cyclin $\mathrm{T}$ proteins in regulating HIV-1 tat-activation. J. Mol. Biol. 288, 57-69. doi: 10.1006/jmbi. 1999.2664

LaBonte, J. A., Babcock, G. J., Patel, T., and Sodroski, J. (2002). Blockade of HIV-1 infection of New World monkey cells occurs primarily at the stage of virus entry. J. Exp. Med 196, 431-445. doi: 10.1084/jem. 20020468

Laguette, N., Rahm, N., Sobhian, B. Chable-Bessia, C., Munch, J., Snoeck, J., et al. (2012). Evolutionary and functional analyses of the interaction between the myeloid restriction factor SAMHD1 and the lentiviral Vpx protein. Cell Host Microbe 11, 205-217. doi: 10.1016/j.chom.2012. 01.007

Laguette, N., Sobhian, B., Casartelli, N., Ringeard, M., Chable-Bessia, C. Segeral, E., et al. (2011). SAMHD1 is the dendritic- and myeloid-cellspecific HIV-1 restriction factor counteracted by Vpx. Nature 474, 654-657. doi: 10.1038/nature10117

Lahouassa, H., Daddacha, W., Hofmann, H., Ayinde, D., Logue, E. C., Dragin, L., et al. (2012). SAMHD1 restricts the replication of human immunodeficiency virus type 1 by depleting the intracellular pool of deoxynucleoside triphosphates. Nat. Immunol. 13, 223-228. doi: 10.1038/ni.2236

Le Tortorec, A., and Neil, S. J. (2009). Antagonism to and intracellular sequestration of human tetherin by the human immunodeficiency virus type 2 envelope glycoprotein. J. Virol. 83, 11966-11978. doi: 10.1128/JVI.01515-09

Letvin, N. L., Daniel, M. D., Sehgal, P. K., Desrosiers, R. C., Hunt, R. D., Waldron, L. M., et al. (1985). Induction of AIDS-like disease in macaque monkeys with $\mathrm{T}$ cell tropic retrovirus STLV-III. Science 230, 71-73. doi: 10.1126/science. 2412295

Letvin, N. L., Montefiori, D. C., Yasutomi, Y., Perry, H. C., Davies, M. E., Lekutis, C., et al. (1997). Potent, protective anti-HIV immune responses generated by bimodal HIV envelope DNA plus protein vaccination. Proc. Natl. Acad. Sci. U.S.A. 94, 9378-9383. doi: 10.1073/pnas.94. 17.9378

Liao, C. H., Kuang, Y. Q., Liu, H. L., Zheng, Y. T., and Su, B. (2007). A novel fusion gene, TRIM5Cyclophilin A in the pig-tailed macaque determines its susceptibility to HIV-1 infection. AIDS 21(Suppl. 8), S19-S26. doi: 10.1097/01.aids. 0000304692.09143.1b

Liddament, M. T., Brown, W. L., Schumacher, A. J., and Harris, R. S. (2004). APOBEC3F properties and hypermutation preferences indicate activity against HIV-1 in vivo. Curr. Biol. 14, 1385-1391. doi: 10.1016/j.cub.2004.06.050

Lim, E. S., Fregoso, O. I., Mccoy, C. O., Matsen, F. A., Malik, H. S., and Emerman, M. (2012). The ability of primate lentiviruses to degrade the monocyte restriction factor SAMHD1 preceded the birth of the viral accessory protein Vpx. Cell Host Microbe 11, 194-204. doi: 10.1016/j.chom.2012. 01.004

Lusso, P., Markham, P. D., Ranki, A., Earl, P., Moss, B., Dorner, F., et al. (1988). Cell-mediated immune response toward viral envelope and core antigens in gibbon apes (Hylobates lar) chronically infected with 
human immunodeficiency virus-1. J. Immunol. 141, 2467-2473. doi: $10.1126 /$ science. 1621083

Madani, N., and Kabat, D. (1998). An endogenous inhibitor of human immunodeficiency virus in human lymphocytes is overcome by the viral Vif protein. J. Virol. 72, 10251-10255. doi: $10.1038 /$ nature00939

Maegawa, H., Nakayama, E. E., Kuroishi, A., and Shioda, T. (2008). Silencing of tripartite motif protein (TRIM) $5 \alpha$ mediated anti-HIV1 activity by truncated mutant of TRIM5 $\alpha . J$. Virol. Methods 151, 249 256. doi: 10.1016/j.jviromet.2008. 04.012

Mariani, R., Chen, D., Schrofelbauer, B., Navarro, F., Konig, R., Bollman, B., et al. (2003). Speciesspecific exclusion of APOBEC3G from HIV-1 virions by Vif. Cell 114 21-31. doi: 10.1016/S0092-8674(03) 00515-4

Marsden, M. D., Kovochich, M., Suree, N., Shimizu, S., Mehta, R., Cortado, R., et al. (2012). HIV latency in the humanized BLT mouse. J. Virol. 86, 339-347. doi: 10.1128/JVI. 06366-11

Matsuda, K., Inaba, K., Fukazawa, Y., Matsuyama, M., Ibuki, K., Horiike, M., et al. (2010). In vivo analysis of a new R5 tropic SHIV generated from the highly pathogenic SHIV-KS661, a derivative of SHIV-89.6. Virology 399, 134-143. doi: 10.1016/j.virol.2010. 01.008

McCune, J. M. (2001). The dynamics of CD4+ T-cell depletion in HIV disease. Nature 410, 974-979. doi: 10.1038/35073648

McNatt, M. W., Zang, T., Hatziioannou, T., Bartlett, M., Fofana, I. B., Johnson, W. E., et al. (2009). Species-specific activity of HIV-1 Vpu and positive selection of tetherin transmembrane domain variants. PLoS Pathog. 5:e1000300. doi: 10.1371/journal. ppat. 1000300

Mehle, A., Strack, B., Ancuta, P., Zhang, C., Mcpike, M., and Gabuzda, D. (2004). Vif overcomes the innate antiviral activity of APOBEC3G by promoting its degradation in the ubiquitin-proteasome pathway. $J$. Biol. Chem. 279, 7792-7798. doi: 10.1074/jbc.M313093200

Melkus, M. W., Estes, J. D., PadgettThomas, A., Gatlin, J., Denton, P. W., Othieno, F. A., et al. (2006). Humanized mice mount specific adaptive and innate immune responses to EBV and TSST-1. Nat. Med. 12, 13161322. doi: 10.1038/nm1431

Mercenne, G., Bernacchi, S., Richer, D., Bec, G., Henriet, S., Paillart, J. C., et al. (2010). HIV-1 Vif binds to APOBEC3G mRNA and inhibits its translation. Nucleic Acids Res. 38, 633-646. doi: 10.1093/nar/ gkp1009

Mische, C. C., Javanbakht, H., Song B., Diaz-Griffero, F., Stremlau, M. Strack, B., et al. (2005). Retroviral restriction factor TRIM5alpha is a trimer. J. Virol. 79, 1444614450. doi: 10.1128/JVI.79.22.1444614450.2005

Miyagi, E., Brown, C. R., Opi, S. Khan, M., Goila-Gaur, R., Kao, S., etal. (2010). Stably expressed APOBEC3F has negligible antiviral activity. J. Virol. 84, 11067-11075. doi: 10.1128/JVI.01249-10

Moldt, B., Rakasz, E. G., Schultz, N., Chan-Hui, P. Y., Swiderek, K., Weisgrau, K. L., et al. (2012). Highly potent HIV-specific antibody neutralization in vitro translates into effective protection against mucosal SHIV challenge in vivo. Proc. Natl. Acad. Sci. U.S.A. 109, 18921-18925. doi: 10.1073/pnas.1214785109

Mosier, D. E., Gulizia, R. J., Baird, S. M., and Wilson, D. B. (1988). Transfer of a functional human immune system to mice with severe combined immunodeficiency. Nature 335, 256259. doi: 10.1038/335256a0

Munk, C., Brandt, S. M., Lucero, G., and Landau, N. R. (2002). A dominant block to HIV-1 replication at reverse transcription in simian cells. Proc. Natl. Acad. Sci. U.S.A. 99, 13843-13848. doi: 10.1073/pnas. 212400099

Naidu, Y. M., Kestler, H. W. III., Li, Y., Butler, C. V., Silva, D. P., Schmidt, D. K., et al. (1988). Characterization of infectious molecular clones of simian immunodeficiency virus (SIVmac) and human immunodeficiency virus type 2: persistent infection of rhesus monkeys with molecularly cloned SIVmac. J. Virol. 62, 4691-4696. doi: $10.1126 /$ science. 2160735

Nakayama, E. E., and Shioda, T. (2010) Anti-retroviral activity of TRIM5 alpha. Rev. Med. Virol. 20, 77-92. doi: 10.1002/rmv.637

Nara, P. L., Robey, W. G., Arthur, L. O., Asher, D. M., Wolff, A. V. Gibbs, C. J. Jr., et al. (1987). Persistent infection of chimpanzees with human immunodeficiency virus: serological responses and properties of reisolated viruses. J. Virol. 61, 3173-3180. doi: 10.1007/9781-4684-5976-0_4

Neil, S. J., Sandrin, V., Sundquist, W. I., and Bieniasz, P. D. (2007) An interferon-alpha-induced tethering mechanism inhibits HIV-1 and Ebola virus particle release but is counteracted by the HIV-1
Vpu protein. Cell Host Microbe 2, 193-203. doi: 10.1016/j.chom.2007. 08.001

Neil, S. J., Zang, T., and Bieniasz, P. D. (2008). Tetherin inhibits retrovirus release and is antagonized by HIV 1 Vpu. Nature 451, 425-430. doi: 10.1038 /nature06553

Newman, E. N., Holmes, R. K., Craig, H. M., Klein, K. C., Lingappa, J. R., Malim, M. H., etal. (2005). Antiviral function of APOBEC3G can be dissociated from cytidine deaminase activity. Curr. Biol. 15, 166-170. doi: 10.1016/j.cub. 2004.12.068

Newman, R. M., Hall, L., Connole, M., Chen, G. L., Sato, S., Yuste, E., et al. (2006). Balancing selection and the evolution of functional polymorphism in Old World monkey TRIM5alpha. Proc. Natl. Acad. Sci. U.S.A. 103, 19134-19139. doi: $10.1073 /$ pnas.0605838103

Newman, R. M., Hall, L., Kirmaier, A. Pozzi, L. A., Pery, E., Farzan, M., et al. (2008). Evolution of a TRIM5-CypA splice isoform in old world monkeys. PLoS Pathog. 4:e1000003. doi: 10.1371/journal.ppat.1000003

Nishimura, Y., Igarashi, T., Donau, O. K., Buckler-White, A., Buckler, C., Lafont, B. A., et al. (2004). Highly pathogenic SHIVs and SIVs target different CD4+ T cell subsets in rhesus monkeys, explaining their divergent clinical courses. Proc. Natl. Acad. Sci. U.S.A. 101, 12324-12329. doi: 10.1073/pnas.0404620101

Nishimura, Y., Igarashi, T., Haigwood, N., Sadjadpour, R., Plishka, R. J., Buckler-White, A., et al. (2002). Determination of a statistically valid neutralization titer in plasma that confers protection against simian-human immunodeficiency virus challenge following passive transfer of high-titered neutralizing antibodies. J. Virol. 76, 2123 2130. doi: 10.1128/jvi.76.5.2123 2130.2002

Nomaguchi, M., Doi, N., Fujiwara, S., Saito, A., Akari, H. Nakayama, E. E., etal. (2013a). Systemic biological analysis of the mutations in two distinct HIV-1mt genomes occurred during replication in macaque cells. Microbes Infect. 15, 319-328. doi: 10.1016/j.micinf.2013. 01.005

Nomaguchi, M., Yokoyama, M., Kono, K., Nakayama, E. E., Shioda, T., Saito, A., et al. (2013b). Gag-CA Q110D mutation elicits TRIM5-independent enhancement of HIV-1mt replication in macaque cells. Microbes Infect. 15, 56-65. doi: 10.1016/j.micinf.2012. 10.013
North, T. W., Van Rompay, K. K., Higgins, J., Matthews, T. B., Wadford, D. A., Pedersen, N. C., et al. (2005). Suppression of virus load by highly active antiretroviral therapy in rhesus macaques infected with a recombinant simian immunodeficiency virus containing reverse transcriptase from human immunodeficiency virus type 1. J. Virol. 79, 7349-7354. doi: 10.1128/JVI.79.12. 7349-7354.2005

Novembre, F. J., Saucier, M., Anderson, D. C., Klumpp, S. A., O’Neil, S. P., Brown, C. R. III., et al. (1997). Development of AIDS in a chimpanzee infected with human immunodeficiency virus type 1.J. Virol. 71, 4086-4091. doi: 10.1089/ aid.2007.0182

Ohta, Y., Masuda, T., Tsujimoto, H., Ishikawa, K., Kodama, T., Morikawa, S., etal. (1988). Isolation of simian immunodeficiency virus from African green monkeys and seroepidemiologic survey of the virus in various non-human primates. Int. J. Cancer 41, 115-122. doi: 10.1002/ijc.2910410121

O’Neil, S. P., Novembre, F. J., Hill, A. B., Suwyn, C., Hart, C. E., EvansStrickfaden, T., et al. (2000). Progressive infection in a subset of HIV1-positive chimpanzees. J. Infect. Dis. 182, 1051-1062. doi: 10.1086/ 315823

Perez-Caballero, D., Hatziioannou, T., Yang, A., Cowan, S., and Bieniasz, P. D. (2005). Human tripartite motif 5alpha domains responsible for retrovirus restriction activity and specificity. J. Virol. 79, 89698978. doi: 10.1128/JVI.79.14.89698978.2005

Perron, M. J., Stremlau, M., Song, B., Ulm, W., Mulligan, R. C., and Sodroski, J. (2004). TRIM5alpha mediates the postentry block to $\mathrm{N}$ tropic murine leukemia viruses in human cells. Proc. Natl. Acad. Sci. U.S.A. 101, 11827-11832. doi: 10.1073/pnas.0403364101

Pertel, T., Hausmann, S., Morger, D., Zuger, S., Guerra, J., Lascano, J., etal. (2011). TRIM5 is an innate immune sensor for the retrovirus capsid lattice. Nature 472, 361-365. doi: 10.1038/nature09976

Powell, R. D., Holland, P. J., Hollis, T., and Perrino, F. W. (2011). AicardiGoutieres syndrome gene and HIV-1 restriction factor SAMHD1 is a dGTP-regulated deoxynucleotide triphosphohydrolase. J. Biol. Chem. 286, 43596-43600. doi: 10.1074/jbc.C111.317628

Prince, A. M., Horowitz, B., Baker, L., Shulman, R. W., Ralph, H., 
Valinsky, J., et al. (1988). Failure of a human immunodeficiency virus (HIV) immune globulin to protect chimpanzees against experimental challenge with HIV. Proc. Natl. Acad. Sci. U.S.A. 85, 6944-6948. doi: 10.1073/pnas. 85.18.6944

Reimann, K. A., Li, J. T., Veazey, R., Halloran, M., Park, I. W. Karlsson, G. B., etal. (1996). A chimeric simian/human immunodeficiency virus expressing a primary patient human immunodeficiency virus type 1 isolate env causes an AIDS-like disease after in vivo passage in rhesus monkeys. $J$. Virol. 70, 6922-6928. doi: 10.1086/ 512243

Reina, S., Markham, P., Gard, E., Rayed, F., Reitz, M., Gallo, R. C., et al. (1993). Serological, biological, and molecular characterization of New Zealand white rabbits infected by intraperitoneal inoculation with cellfree human immunodeficiency virus. J. Virol. 67, 5367-5374. doi: 10.1089/ aid.1994.10.285

Reymond, A., Meroni, G., Fantozzi, A., Merla, G., Cairo, S., Luzi, L., et al. (2001). The tripartite motif family identifies cell compartments. EMBO J. 20, 2140-2151. doi: 10.1093/emboj/20.9.2140

Reynolds, M. R., Sacha, J. B., Weiler, A. M., Borchardt, G. J., Glidden, C. E., Sheppard, N. C., et al. (2011). The TRIM5\{alpha\} genotype of rhesus macaques affects acquisition of simian immunodeficiency virus SIVsmE660 infection after repeated limiting-dose intrarectal challenge. J. Virol. 85, 9637-9640. doi: 10.1128/JVI.05074-11

Rice, G. I., Bond, J., Asipu, A., Brunette, R. L., Manfield, I. W., Carr, I. M., et al. (2009). Mutations involved in Aicardi-Goutieres syndrome implicate SAMHD1 as regulator of the innate immune response. Nat. Genet. 41, 829-832. doi: 10.1038/ ng. 373

Saito, A., Kawamoto, Y., Higashino, A., Yoshida, T., Ikoma, T., Suzaki, Y., etal. (2012a). Allele frequency of antiretroviral host factor TRIMCyp in wild-caught cynomolgus macaques (Macaca fascicularis). Front. Microbiol. 3:314. doi: 10.3389/fmicb.2012.00314

Saito, A., Kono, K., Nomaguchi, M., Yasutomi, Y., Adachi, A., Shioda, T., et al. (2012b). Geographical, genetic and functional diversity of antiretroviral host factor TRIMCyp in cynomolgus macaque (Macaca fascicularis). J. Gen. Virol. 93, 594-602. doi: 10.1099/vir.0.038075-0
Saito, A., Nomaguchi, M., Iijima, S., Kuroishi, A., Yoshida, T., Lee, Y. J., et al. (2011). Improved capacity of a monkey-tropic HIV-1 derivative to replicate in cynomolgus monkeys with minimal modifications. Microbes Infect. 13, 58-64. doi: 10.1016/j.micinf. 2010.10.001

Saito, A., Nomaguchi, M., Kono, K., Iwatani, Y., Yokoyama, M., Yasutomi, Y., et al. (2013). TRIM5 genotypes in cynomolgus monkeys primarily influence inter-individual diversity in susceptibility to monkey-tropic human immunodeficiency virus type 1. J. Gen. Virol. 94, 1318-1324. doi: 10.1099/vir.0.050252-0

Sakai, H., Shibata, R., Sakuragi, J., Sakuragi, S., Kawamura, M. and Adachi, A. (1993). Celldependent requirement of human immunodeficiency virus type 1 Vif protein for maturation of virus particles. J. Virol. 67, 16631666. doi: 10.1128/JVI.75.16.72527265.2001

Sakai, H., Tokunaga, K., Kawamura M., and Adachi, A. (1995). Function of human immunodeficiency virus type $1 \mathrm{Vpu}$ protein in various cell types. J. Gen. Virol. 76(Pt 11), 2717-2722. doi: 10.1099/0022-131776-11-2717

Sakuma, R., Mael, A. A., and Ikeda, Y. (2007). Alpha interferon enhances TRIM5alpha-mediated antiviral activities in human and rhesus monkey cells. J. Virol. 81, 10201-10206. doi: 10.1128/JVI.00419-07

Sato, K., Misawa, N., Fukuhara, M. Iwami, S., An, D. S., Ito, M., et al. (2012). Vpu augments the initial burst phase of HIV-1 propagation and downregulates BST2 and CD4 in humanized mice. J. Virol. 86, 5000-5013. doi: 10.1128/JVI 07062-11

Sauter, D., Schindler, M., Specht, A., Landford, W. N., Munch, J., Kim, K. A., et al. (2009). Tetherin-driven adaptation of $\mathrm{Vpu}$ and Nef function and the evolution of pandemic and nonpandemic HIV-1 strains. Cell Host Microbe 6, 409-421. doi: 10.1016/j.chom.2009. 10.004

Sayah, D. M., Sokolskaja, E., Berthoux, L., and Luban, J. (2004). Cyclophilin A retrotransposition into TRIM5 explains owl monkey resistance to HIV-1. Nature 430, 569-573. doi: 10.1038 /nature 02777

Schmitt, K., Guo, K., Algaier, M., Ruiz, A., Cheng, F., Qiu, J., et al. (2011). Differential virus restriction patterns of rhesus macaque and human APOBEC3A: implications for lentivirus evolution. Virology 419, 24-42. doi: 10.1016/j.virol.2011.07.017

Schrofelbauer, B., Senger, T., Manning, G., and Landau, N. R. (2006). Mutational alteration of human immunodeficiency virus type 1 Vif allows for functional interaction with nonhuman primate APOBEC3G. J. Virol. 80, 5984-5991. doi: 10.1128/JVI. 00388-06

Schuitemaker, H., Koot, M., Kootstra, N. A., Dercksen, M. W., De Goede, R. E., Van Steenwijk, R. P., et al. (1992). Biological phenotype of human immunodeficiency virus type 1 clones at different stages of infection: progression of disease is associated with a shift from monocytotropic to T-cell-tropic virus population. J. Virol. 66, 1354-1360. doi: 10.1038/nm0398-346

Serra-Moreno, R., Jia, B., Breed, M., Alvarez, X., and Evans, D. T. (2011). Compensatory changes in the cytoplasmic tail of gp41 confer resistance to tetherin/BST2 in a pathogenic nef-deleted SIV. Cell Host Microbe 9, 46-57. doi: 10.1016/j.chom.2010.12.005

Sheehy, A. M., Gaddis, N. C., Choi, J. D., and Malim, M. H. (2002). Isolation of a human gene that inhibits HIV-1 infection and is suppressed by the viral Vif protein. Nature 418, 646-650. doi: 10.1038/ nature00939

Shibata, R., and Adachi, A. (1992). SIV/HIV recombinants and thei use in studying biological properties. AIDS Res. Hum. Retro viruses 8, 403-409. doi: 10.1089/aid. 1992.8.403

Shibata, R., Igarashi, T., Haigwood, N., Buckler-White, A., Ogert, R. Ross, W., et al. (1999). Neutralizing antibody directed against the HIV1 envelope glycoprotein can completely block HIV-1/SIV chimeric virus infections of macaque monkeys. Nat. Med. 5, 204-210. doi: $10.1038 / 5568$

Shibata, R., Kawamura, M., Sakai, H., Hayami, M., Ishimoto, A. and Adachi, A. (1991). Generation of a chimeric human and simian immunodeficiency virus infectious to monkey peripheral blood mononuclear cells. J. Virol. 65 , 3514-3520. doi: 10.1128/JVI.77.1. 726-731.2003

Shibata, R., Sakai, H., Kawamura, M., Tokunaga, K., and Adachi, A. (1995). Early replication block of human immunodeficiency virus type 1 in monkey cells. J. Gen. Virol. 76, 2723 2730. doi: 10.1099/0022-1317-76-112723
Shingai, M., Yoshida, T., Martin, M A., and Strebel, K. (2011). Some human immunodeficiency virus type $1 \mathrm{Vpu}$ proteins are able to antagonize macaque BST-2 in vitro and in vivo: Vpu-negative simian-human immunodeficiency viruses are attenuated in vivo. J. Virol. 85, 9708-9715. doi: 10.1128/JVI.00626-11

Shultz, L. D., Lyons, B. L., Burzenski, L. M., Gott, B., Chen, X., Chaleff, S., et al. (2005). Human lymphoid and myeloid cell development in NOD/LtSz-scid IL2R gamma null mice engrafted with mobilized human hemopoietic stem cells. J. Immunol. 174, 6477-6489. doi: 10.3410/f.1003045. 323931

Simon, J. H., Gaddis, N. C., Fouchier, R. A., and Malim, M. H. (1998). Evidence for a newly discovered cellular anti-HIV-1 phenotype. Nat. Med. 4, 1397-1400. doi: 10.1038/3987

Speck, R. F., Penn, M. L., Wimmer, J., Esser, U., Hague, B. F., Kindt, T. J., et al. (1998). Rabbit cells expressing human CD4 and human CCR5 are highly permissive for human immunodeficiency virus type 1 infection. J. Virol. 72, 5728-5734. doi: 10.1186/1742-4690-4-53

Stremlau, M., Owens, C. M., Perron, M. J., Kiessling, M., Autissier, P., and Sodroski, J. (2004). The cytoplasmic body component TRIM5alpha restricts HIV-1 infection in Old World monkeys. Nature 427, 848-853. doi: 10.1038/ nature 02343

Tanaka, Y., Marusawa, H., Seno, H., Matsumoto, Y., Ueda, Y., Kodama, Y., et al. (2006). Anti-viral protein APOBEC3G is induced by interferonalpha stimulation in human hepatocytes. Biochem. Biophys. Res. Commun. 341, 314-319. doi: 10.1016/j. bbrc.2005.12.192

Tervo, H. M., and Keppler, O. T. (2010). High natural permissivity of primary rabbit cells for HIV-1, with a virion infectivity defect in macrophages as the final replication barrier. J. Virol. 84, 12300-12314. doi: 10.1128/JVI.01607-10

Thippeshappa, R., Polacino, P., Yu Kimata, M. T., Siwak, E. B., Anderson, D., Wang, W., et al. (2011). Vif substitution enables persistent infection of pig-tailed macaques by human immunodeficiency virus type 1. J. Virol. 85, 3767-3779. doi: 10.1128/JVI.02438-10

Traggiai, E., Chicha, L., Mazzucchelli, L., Bronz, L., Piffaretti, J. C., Lanzavecchia, A., et al. (2004). Development of a human adaptive immune system in cord blood cell-transplanted 
mice. Science 304, 104-107. doi: 10.1126/science.1093933

Uberla, K., Stahl-Hennig, C., Bottiger, D., Matz-Rensing, K., Kaup, F. J., Li, J., etal. (1995). Animal model for the therapy of acquired immunodeficiency syndrome with reverse transcriptase inhibitors. Proc. Natl. Acad. Sci. U.S.A. 92, 8210-8214. doi: 10.1073/pnas.92.18.8210

Van Damme, N., Goff, D., Katsura, C., Jorgenson, R. L., Mitchell, R., Johnson, M. C., et al. (2008). The interferon-induced protein BST2 restricts HIV-1 release and is downregulated from the cell surface by the viral Vpu protein. Cell Host Microbe 3, 245-252. doi: 10.1016/j.chom.2008.03.001

Virgen, C. A., and Hatziioannou, T. (2007). Antiretroviral activity and Vif sensitivity of rhesus macaque APOBEC3 proteins. J. Virol. 81, 13932-13937. doi: 10.1128/ JVI.01760-07

Virgen, C. A., Kratovac, Z., Bieniasz, P. D., and Hatziioannou, T. (2008). Independent genesis of chimeric TRIM5-cyclophilin proteins in two primate species. Proc. Natl. Acad. Sci. U.S.A. 105, 3563-3568. doi: $10.1073 /$ pnas.0709258105
Wiegand, H. L., Doehle, B. P., Bogerd, H. P., and Cullen, B. R. (2004). A second human antiretroviral factor, APOBEC3F, is suppressed by the HIV-1 and HIV-2 Vif proteins. EMBO J. 23, 2451-2458. doi 10.1038/sj.emboj.7600246

Wilson, S. J., Webb, B. L., Ylinen, L. M., Verschoor, E., Heeney, J. L., and Towers, G. J. (2008). Independent evolution of an antiviral TRIMCyp in rhesus macaques. Proc. Natl. Acad. Sci. U.S.A. 105, 3557-3562. doi: 10.1073/pnas.0709003105

Wyand, M. S., Manson, K., Montefiori, D. C., Lifson, J. D., Johnson, R. P., and Desrosiers, R. C. (1999). Protection by live, attenuated simian immunodeficiency virus against heterologous challenge. J. Virol. 73, 8356-8363. doi: 10.1371/journal.pone.0023092

Wyand, M. S., Manson, K. H. Garcia-Moll, M., Montefiori, D. and Desrosiers, R. C. (1996). Vaccine protection by a triple deletion mutant of simian immunodeficiency virus. J. Virol. 70, 3724-3733. doi: 10.1038/nm0197-32

Yap, M. W., Nisole, S., Lynch, C., and Stoye, J. P. (2004). Trim5alpha protein restricts both HIV-1 and murine leukemia virus. Proc. Nat. Acad.
Sci. U.S.A. 101, 10786-10791. doi: 10.1073/pnas.0402876101

Ylinen, L. M., Price, A. J., Rasaiyaah, J., Hue, S., Rose, N. J., Marzetta, F. et al. (2010). Conformational adaptation of Asian macaque TRIMCyp directs lineage specific antiviral activity. PLoS Pathog. 6:e1001062. doi: 10.1371/journal.ppat.1001062

Zennou, V., and Bieniasz, P. D. (2006). Comparative analysis of the antiretroviral activity of APOBEC3G and APOBEC3F from primates. Virology 349, 31-40. doi: 10.1016/j.virol.2005.12.035

Zhang, F., Wilson, S. J., Landford, W. C., Virgen, B., Gregory, D. Johnson, M. C., etal. (2009). Nef proteins from simian immunodeficiency viruses are tetherin antagonists. Cell Host Microbe 6, 54-67. doi: 10.1016/j.chom.2009.05.008

Zhao, C., Collins, M. N., Hsiang, T. Y., and Krug, R. M. (2013). Interferon-induced ISG15 pathway: an ongoing virus-host battle. Trends Microbiol. 21, 181-186. doi: 10.1016/j.tim.2013.01.005

Zheng, Y. H., Irwin, D., Kurosu, T. Tokunaga, K., Sata, T., and Peterlin, B. M. (2004). Human APOBEC3F is another host factor that blocks human immunodeficiency virus type 1 replication. J. Virol. 78, 60736076. doi: 10.1128/JVI.78.11.6073 6076.2004

Conflict of Interest Statement: The authors declare that the research was conducted in the absence of any commercial or financial relationships that could be construed as a potential conflict of interest.

Received: 26 April 2013; paper pending published: 14 May 2013; accepted: 20 June 2013; published online: 09 July 2013. Citation: Saito A and Akari H (2013) Macaque-tropic human immunodeficiency virus type 1: breaking out of the host restriction factors. Front. Microbiol. 4:187. doi: 10.3389/fmicb.2013.00187

This article was submitted to Frontiers in Virology, a specialty of Frontiers in Microbiology.

Copyright (c) 2013 Saito and Akari. This is an open-access article distributed under the terms of the Creative Commons Attribution License, which permits use, distribution and reproduction in other forums, provided the original authors and source are credited and subject to any copyright notices concerning any thirdparty graphics etc. 